\title{
Effects of 4-Methylcyclohexanemethanol on Stress Response Pathway Regulators, in Saccharomyces Cerevisiae
}

\author{
Suk Lan Ser \\ West Virginia University, suser@mix.wvu.edu
}

Follow this and additional works at: https://researchrepository.wvu.edu/etd

Part of the Genetics Commons, Genomics Commons, Molecular Genetics Commons, and the Systems Biology Commons

\section{Recommended Citation}

Ser, Suk Lan, "Effects of 4-Methylcyclohexanemethanol on Stress Response Pathway Regulators, in Saccharomyces Cerevisiae" (2021). Graduate Theses, Dissertations, and Problem Reports. 8303. https://researchrepository.wvu.edu/etd/8303

This Thesis is protected by copyright and/or related rights. It has been brought to you by the The Research Repository @ WVU with permission from the rights-holder(s). You are free to use this Thesis in any way that is permitted by the copyright and related rights legislation that applies to your use. For other uses you must obtain permission from the rights-holder(s) directly, unless additional rights are indicated by a Creative Commons license in the record and/ or on the work itself. This Thesis has been accepted for inclusion in WVU Graduate Theses, Dissertations, and Problem Reports collection by an authorized administrator of The Research Repository @ WVU. For more information, please contact researchrepository@mail.wvu.edu. 
Effects of 4-Methylcyclohexanemethanol on Stress Response

Pathway Regulators, in Saccharomyces Cerevisiae

Suk Lan Ser

Follow this and additional works at: https://researchrepository.wvu.edu/etd

Part of the Genetics Commons, Genomics Commons, Molecular Genetics Commons, and the Systems Biology Commons 


\title{
EFFECTS OF 4-METHYLCYCLOHEXANEMETHANOL ON STRESS RESPONSE PATHWAY REGULATORS, IN SACCHAROMYCES CEREVISIAE
}

\author{
Suk Lan Ser \\ Thesis submitted to the Eberly College of Arts and Sciences \\ At West Virginia University \\ in partial fulfillment of the requirements for the degree of
}
Master of Science
In Biology

\author{
Jennifer Gallagher, Ph.D., Chair \\ Daniel Panaccione, Ph.D. \\ Sadie Bergeron, Ph.D.
}

Department of Biology

Morgantown, West Virginia

2021

Keywords: Saccharomyces cerevisiae, 4-methylycyclohexanemethanol (MCHM), stress response pathway, transcription, SNF1, hydrotrope, MED15, polyQ tracts

Copyright 2021 Suk Lan Ser 


\title{
ABSTRACT \\ Effects Of 4-Methylcyclohexanemethanol On Stress Response Pathway Regulators, In Saccharomyces Cerevisiae
}

\author{
Suk Lan Ser
}

Hydrotropes are small molecules capable of inducing liquid-liquid phase separation by altering the solubility and conformation states of organic compounds that are increasingly becoming important in organizing chemical reactions and regulating complexes. They prevent protein aggregation causing these proteins to form condensates. Mediator, a highly conserved multi-subunit complex, plays an important role in transcription. Med15, a subunit found within the tail domain of the Mediator complex, works with stress-induced transcription factors and is regulated by many kinases, including CDKs and the AMP kinase, Snf1. Living cells respond by changing molecular and cellular pathways when they are exposed to stressful conditions. Damage to intracellular molecules depends on the duration of stress exposure and the severity of the stressor. By studying cellular stress response through the Mediator complex in Saccharomyces cerevisiae, the molecular effects of MCHM (4-methylcyclohexanemethanol), a synthetic hydrotrope, can be determined. The hydrotropic nature of MCHM and how it interacted with the polymorphic polyQ tracts of Med15 likely caused protein folding aggregation, which eventually led to protein condensates. The tolerance towards MCHM and other chemical stressors such as 4-nitroquinoline-1-oxide (4NQO), hydrogen peroxide $\left(\mathrm{H}_{2} \mathrm{O}_{2}\right)$, and hygromycin (HYG) are dependent on the genetic variation of Med15's polyQ tract and the presence of Snf1. Genetic variations of Med15 influence the formation of LLPS by affecting how the fuzzy domains, which include the polyQ tracts of the subunit, interact with hydrotropes. These findings combined to characterize how different alleles of Med15 deal with stress-inducing conditions by studying its interactions with a hydrotrope like MCHM. 


\section{ACKNOWLEDGEMENTS}

Throughout this journey, I've had the support and encouragement of some remarkable individuals who have made this thesis possible. First and foremost, I would like to extend my deepest gratitude to my advisor, Dr. Jennifer Gallagher. She has been there for me throughout the ups and downs of not just my academic life but my life in general for the past three years. I love her willingness to go out of her way to help her students and truly invest her time to make sure they succeed. Jen has the ability to instill confidence in a person even when they didn't believe they could achieve something. She has certainly inspired me to be a better researcher and a better person altogether.

I also have to thank my committee members, Dr. Daniel Panaccione and Dr. Sadie Bergeron, for offering their guidance and advice throughout my graduate studies. I had the opportunity to attend two of Dr.Panaccione's classes and had so much fun learning from him. I would like to further extend my gratitude to Dr.Rita Rio, who taught me the basics of virology and infectious diseases. She is the reason why I fell in love with that particular field of study and decided to pursue a Ph.D. in infectious diseases.

To the past and present members of the Gallagher lab, I would like to thank everyone for creating a great and cordial working environment. Apoorva Ravishankar and Michael Ayers were such amazing mentors taking time off their research to assist me with mine. Taizina Momtareen, who I'll miss dearly, has not just been an awesome lab mate but also a great friend. She's been the one I relied on for autoclave visits, picture taking of plates, and the list goes on. To Scott Arbet, Matt Winans, and the rest of the Gallagher lab, you have my 
utmost gratitude for the cherished time spent together as lab mates and friends. I hope to find a lab just like this at Penn State.

I am so thankful to some of my friends that I've met at the department as a graduate student. Emel Kangi and her husband, Philip, have been absolute gems since day one. Emel has been a hub of information to me, from getting a driver's license to filing taxes. As one of my closest friends, I have shared my achievements and downfalls with her as both a graduate student and an adult in general. I have been so fortunate to have met such a kind and honest soul. I would also like to thank a few others who have made my journey at WVU a memorable one: Miguel Medina Munoz and Hana Thixton. We've all shared advice, jokes, and rants about being in graduate school.

To my friends back home who have kept me sane throughout my entire education life, I'm so lucky to have you guys as friends. My best friend since I was 11 , Rachel Loh, has always made me laugh and feel like the world is a better place, even at the darkest times. I am glad I have been able to bribe her to be my friend with those leftover Murray mints when I first met her. Jia Min and Yi Xin have both been incredible friends and have always made sure I was doing well no matter where I was. True friends are never apart, maybe in distance but never at heart.

I am deeply indebted to the doctors and nurses back home who saved my life and made sure the battle I fought was not a lonely one. Their tenderness, resilience, and compassion have made every surgery and treatment a little less painful for the past seven months. I'm 
so fortunate to have been born in a country where a patient's health and their concerns are met with immediate response and that it matters more than their insurance coverage. Lastly, I would like to thank the four most influential people in my life who have been a pillar of strength and have showered me with love like no other. My mother, who has selflessly placed me first above anyone and anything else since the day I was born, my appreciation for the unparalleled love and support she has given me will never be enough. To my father, who has given me a wonderful and comfortable life no matter how tired he is, I hope I have made him proud. The two greatest gifts that l've ever received, as annoying as they can be, my sisters have always brought joy to my life. To the world, you may be just one person, but to one person, you may be the world. 
This thesis is dedicated to my family, whom I don't thank enough,

\author{
My father, Ser Ah Ching \\ My mother, Shamala Kalimuthu \\ My sisters, Suk Ying and Suk Yee
}

Thank you for all your unparalleled love, support, and encouragement. 


\section{TABLE OF CONTENTS}

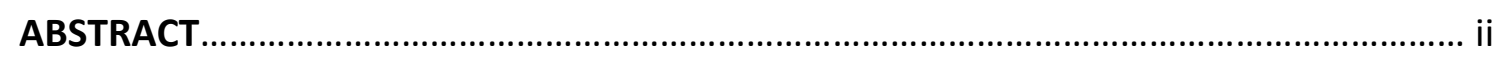

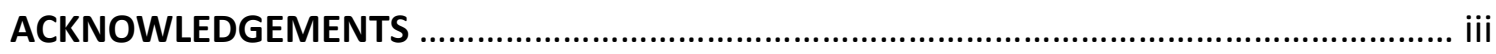

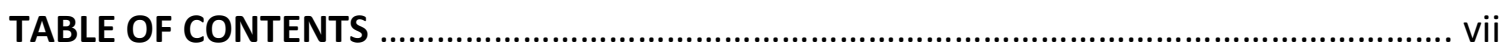

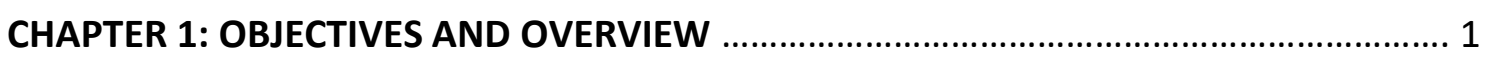

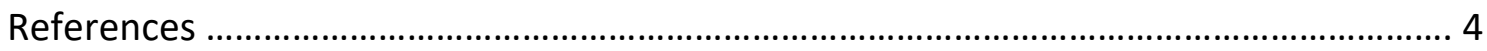

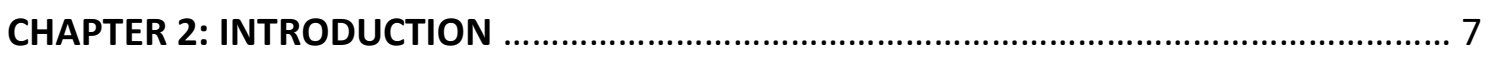

Yeast As An Ideal Model Organism And Its Genetic Diversity ........................................... 7

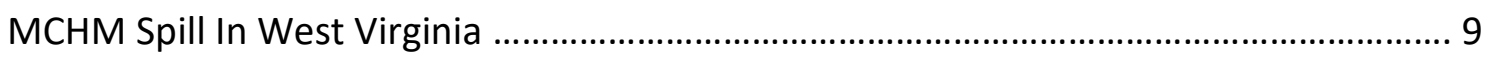

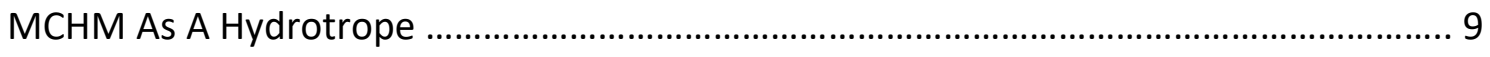

Mediator, A Complex Involved In Transcription Regulation ............................................ 11

Med15 And Its Interaction With Stress Response Transcription Factors ........................... 12

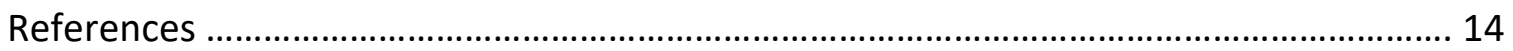

CHAPTER 3: THE POLYMORPHIC POLYQ TAIL PROTEIN OF THE MEDIATOR COMPLEX, MED15, REGULATES VARIABLE RESPONSE TO DIVERSE STRESSES ….......................... 20

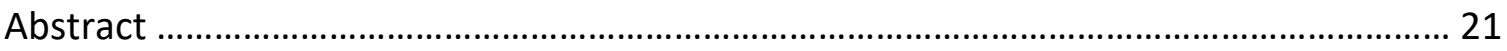

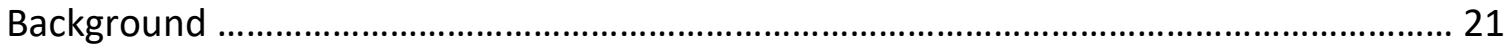

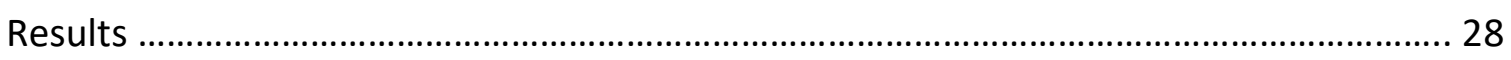

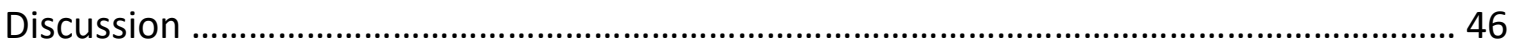

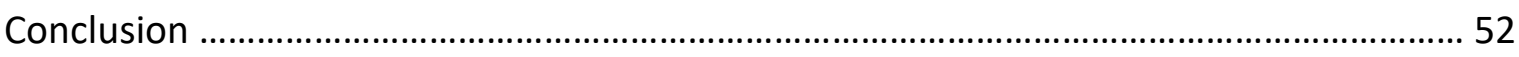

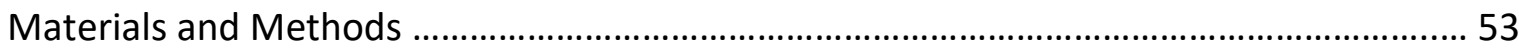

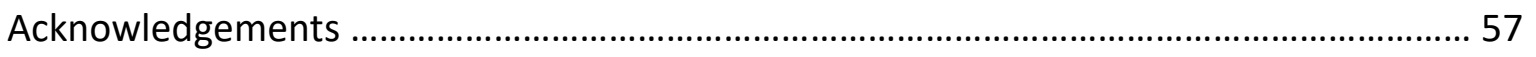

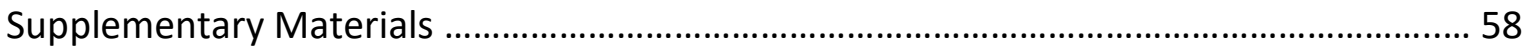


References

CHAPTER 4: PROXIMITY LABELLING OF MED15 TO DETERMINE ITS INTERACTIONS

Abstract 69

Introduction 69

Materials and Methods 73

Results 75

Discussion 76

References 77

CHAPTER 5: CONCLUSION 81

References 85 


\section{CHAPTER 1: OBJECTIVES AND OVERVIEW}

Cells utilize a diverse range of regulatory strategies to ensure survival and maintain homeostasis under stressful conditions. These adaptations often depend on the type of damage that has been caused or will be caused by a particular stressor and the organism's genetic makeup. If we focused on the genetic makeup aspect, variations within the organism's genome would allow for phenotypic differences. In other words, a variation at a genetic level leads to a variation in a given phenotype (Orgogozo et al., 2015). A paradigm of this stress signaling pathway is best studied using yeast cells as it is well conserved across most eukaryotes.

The focus of my project is on an industrial solvent called 4-methylcyclohexanemethanol (MCHM) that is used as a froth floatation to clean coal. In previous studies, MCHM was identified as a hydrotrope capable of preventing protein aggregation, which can affect protein function (Pupo et al., 2020). Like other biological hydrotropes such as ATP and RNA, MCHM increases the solubility of organic compounds by inducing liquid-liquid phase separation (LLPS). This phenomenon is thought to drive membraneless compartmentalization in cells by physically pushing molecules into different solubilities or conformation states (Alberti et al., 2019). However, unlike ATP (Kang et al., 2018; Patel et al., 2017) and RNA (Lin et al., 2015), MCHM is not readily metabolized in cells and therefore makes an ideal synthetic hydrotrope model for understanding how LLPS regulates stress response (Pupo et al., 2019). 
Approximately 10,000 gallons of this licorice-like odor chemical were spilled into the Elk River in West Virginia in January 2014, contaminating the drinking-water supplies of at least 300,000 residents. Many people suffered from various illnesses, including mild skin irritation and gastrointestinal issues (Thomasson et al., 2017). Months after the spill, the National Toxicology Program (NTP) reported reduced fetal birth weight and skeletal abnormality in rodents (National Toxicology Program, 2020) and photometor effects in zebrafish (Horzmann et al., 2017). Fortunately, due to early detection and implementation of no-use orders, the impact on long-term human health was avoided (Benson et al., 2018; Whelton et al., 2017). Although there has been a number of studies focusing on the toxicological effects of MCHM, there is very little known about the effects of MCHM on cell biology (Perfetto et al., 2020).

I utilized MCHM as a novel stressor to understand the stress response pathway involving the Mediator complex in yeast better to know the effects of MCHM at the cellular level. The main goal of my thesis was to identify the differences in terms of growth phenotype and protein levels of a specific Mediator subunit (Med15) between two genetically diverse yeasts when exposed to MCHM and other common laboratory drugs. Med15 contains a very distinctive amino acid sequence with several repeated glutamine units known as polyQ tracts and a kinase inducible domain (KIX) that interacts with stress response transcription factors (Jedidi et al., 2010; Tuttle et al., 2018). The genetic variation found within the polyQ tracts is what we hypothesize to contribute to the various phenotypic responses seen when yeast cells are forced to deal with stressful conditions.

There are three specific aims as listed below that will help to decipher the specifics of my research goals: 
SPECIFIC AIM 1: Measuring the effects of MCHM by identifying changes in growth phenotype of two genetically different yeast strains.

Med15, a subunit found within the tail module of the Mediator complex, interacts with stress-induced transcription factors (Miller et al., 2012; Jedidi et al., 2010). I hypothesize that the presence of Med15 is crucial for the viability of cells when they are exposed to a hydrotrope stressor like MCHM. Qualitative growth assays of two genetically diverse yeasts containing different alleles of MED15 and other stress response regulators in the presence of MCHM were conducted. I then further studied the influence of the Myc tag (an epitope tag) that was used to tag MED15 alleles at its chromosomal location, because its presence altered the cells' sensitivity towards MCHM.

SPECIFIC AIM 2: Identifying the impact of other stress response regulators, Snf1 and Reg1, on yeast cells expressing different Med15 alleles.

Snf1 is an AMP protein kinase required for regulating metabolism in different carbon sources (Ratnakumar and Young, 2010). Snf1 has been found in large-scale purifications with the Mediator complex and regulates many of the same pathways that also rely on the Mediator complex (Hedbacker and Carlson, 2008). Reg1, a protein required for glucose repression, regulates the activity of protein phosphatase 1 (PP1), which in turn negatively regulates Snf1 by dephosphorylation (Tu and Carlson, 1995). In a reg1 mutant cell, the Snf1 complex is constitutively active. Med15 has several predicted phosphorylation sites likely contributing to multiple isoforms that can be resolved on western blots. To determine the contribution of Snf1 activity, isoforms of Med15 were analyzed in snf1 mutant (loss of Snf1 activity) and reg1 mutant (hyperactivity of Snf1). 
SPECIFIC AIM 3: Evaluate the loss of Snf1 and Reg1 in yeast cells expressing different Med15 alleles in the presence of various stressors.

To assess the role of Snf1 and Reg1 as stress response regulators, a quantitative growth assay was conducted using yeast cells that were either snf1 or reg1 mutants. The influence of genetic variation was further studied once again using different alleles of Med15. Seven common laboratory drugs chosen based on their varying levels of cellular damage served as stressors in the assay. Further analysis was carried out to determine whether Myc tag impacted the sensitivity of these cells towards the stressors, as seen in the MCHM experiments.

\section{REFERENCES}

Alberti, S., Gladfelter, A., and Mittag, T. (2019). Considerations and challenges in studying liquid-liquid phase separation and biomolecular condensates. Cell 176, 419-434.

Hedbacker, K., and Carlson, M. (2008). SNF1/AMPK pathways in yeast. Front Biosci 13, $2408-2420$.

Benson, S.M., Ruestow, P., Keeton, K.A., Novick, R.M., Marsh, G.M., and Paustenbach, D.J. (2018). The 2014 crude 4-methylcyclohexanemethanol chemical release and birth outcomes in West Virginia. Archives of Environmental \& Occupational Health 73, 292-301

Horzmann, K.A., de Perre, C., Lee, L.S., Whelton, A.J., and Freeman, J.L. (2017). Comparative analytical and toxicological assessment of methylcyclohexanemethanol (MCHM) mixtures associated with the Elk River chemical spill. Chemosphere 188, 599-607. 
Jedidi, I., Zhang, F., Qiu, H., Stahl, S.J., Palmer, I., Kaufman, J.D., Nadaud, P.S., Mukherjee, S., Wingfield, P.T., Jaroniec, C.P., et al. (2010). Activator Gcn4 Employs Multiple Segments of Med15/Gal11, Including the KIX Domain, to Recruit Mediator to Target Genes in Vivo. Journal of Biological Chemistry 285, 2438-2455.

Kang, J., Lim, L., and Song, J. (2018). ATP enhances at low concentrations but dissolves at high concentrations liquid-liquid phase separation (LLPS) of ALS/FTD-causing FUS. Biochem Biophys Res Commun 504, 545-551.

Lin, Y., Protter, D.S.W., Rosen, M.K., and Parker, R. (2015). Formation and Maturation of Phase-Separated Liquid Droplets by RNA-Binding Proteins. Mol Cell 60, 208-219.

Miller, C., Matic, I., Maier, K.C., Schwalb, B., Roether, S., Strässer, K., Tresch, A., Mann, M., and Cramer, P. (2012). Mediator Phosphorylation Prevents Stress Response Transcription During Non-stress Conditions. Journal of Biological Chemistry 287, 44017-44026.

National Toxicology Program (2020). NTP Developmental and Reproductive Toxicity Technical Report on the Prenatal Development Studies of 4-Methylcyclohexanemethanol (CASRN 34885-03-5) in Sprague Dawley (Hsd:Sprague Dawley ${ }^{\circledR}$ SD $^{\circledR}$ ) Rats (Gavage Studies): DART Report 02 (Research Triangle Park (NC): National Toxicology Program).

Orgogozo, V., Morizot, B., and Martin, A. (2015). The differential view of genotypephenotype relationships. Front Genet 6 .

Patel, A., Malinovska, L., Saha, S., Wang, J., Alberti, S., Krishnan, Y., and Hyman, A.A. (2017). ATP as a biological hydrotrope. Science $356,753-756$. 
Perfetto, M., Kirkham, S.G., Ayers, M.C., Wei, S., and Gallagher, J.E.G. (2020). 4-

Methylcyclohexane methanol (MCHM) affects viability, development, and movement of Xenopus embryos. Toxicol Rep 8, 38-43

Pupo, A., Ku, K.M., and Gallagher, J.E.G. (2019). Effects of MCHM on yeast metabolism. PLoS One 14.

Pupo, A., Ayers, M.C., Sherman, Z.N., Vance, R.J., Cumming, J.R., and Gallagher, J.E.G. (2020). MCHM Acts as a Hydrotrope, Altering the Balance of Metals in Yeast. Biol Trace Elem Res 195, 260-271.

Ratnakumar, S., and Young, E.T. (2010). Snf1 Dependence of Peroxisomal Gene Expression Is Mediated by Adr1*. Journal of Biological Chemistry 285, 10703-10714.

Thomasson, E.D., Scharman, E., Fechter-Leggett, E., Bixler, D., Ibrahim, S., Duncan, M.A., Hsu, J., Scott, M., Wilson, S., Haddy, L., et al. (2017). Acute Health Effects After the Elk River Chemical Spill, West Virginia, January 2014. Public Health Rep 132, 196-202.

Tu, J., and Carlson, M. (1995). REG1 binds to protein phosphatase type 1 and regulates glucose repression in Saccharomyces cerevisiae. EMBO J 14, 5939-5946.

Tuttle, L.M., Pacheco, D., Warfield, L., Luo, J., Ranish, J., Hahn, S., and Klevit, R.E. (2018). Gcn4-Mediator Specificity Is Mediated by a Large and Dynamic Fuzzy Protein-Protein Complex. Cell Reports 22, 3251-3264.

Whelton, A.J., McMillan, L., Novy, C.L.-R., White, K.D., and Huang, X. (2017). Case study: the crude MCHM chemical spill investigation and recovery in West Virginia USA. Environ. Sci.: Water Res. Technol. 3, 312-332. 


\section{CHAPTER 2: INTRODUCTION}

\section{YEAST AS AN IDEAL MODEL ORGANISM AND ITS GENETIC DIVERSITY}

Yeast has been domesticated and utilized for the benefit of mankind for centuries, whether in bread making or beer brewing. Baker's yeast, also known as Saccharomyces cerevisiae, has been the ideal eukaryotic model organism for modern biology for decades since the birth of a new field that combined genetics, biochemistry, and recombinant DNA techniques (Duina et al., 2014; Botstein et al., 1997). Its statistically high homology between its proteinencoding gene sequences and mammalian protein sequences explains its highly conserved fundamental cellular mechanisms (Botstein et al., 1997; Liu et al., 2017). Some of those shared genes include stress response genes and core housekeeping genes (Engel and Cherry, 2013).

Besides being cheap and having a short generation time, the extensive genetic and phenotypic diversity within the organism makes S. cerevisiae one of the most studied models. Despite having only a genome size of 12 million base pairs comprising 6275 genes, the genetic diversity between two strains can be as variable as 60,000 SNPs and 6,000 indels (Wei et al., 2007). These genotypic differences are followed by diverse phenotypic changes that can be studied in salt and $\mathrm{pH}$ tolerance, chemical and drug resistance, nutrient utilization, and other phenotypic traits (Botstein and Fink, 2011).

Not only can we establish the relationship between genes and cellular traits, but $S$. cerevisiae also allows for the establishment of the relationship between gene structure and protein function. In fact, many eukaryotic gene functions were determined through 
experiments involving yeast (Botstein et al., 1997). The genetic variation within S. cerevisiae conveniently allows for studying different cellular pathways and their interaction between each network. For example, we can look at different yeast strains and their sensitivity towards a particular chemical or drug to tease out links between genotype and phenotype. Each strain may utilize pathways unique to itself to metabolize these foreign stressors based on their genetic variation. For example, one strain sensitive to a DNA damaging agent might be resistant to a cell wall damaging agent. As seen in the case of YJM789 and S288c, the two common laboratory yeast strains that were focused on for this thesis.

YJM789 is a clinical isolate obtained from the lungs of an AIDS patient suffering from fungal pneumonia (Tawfik et al., 1989; Wei et al., 2007). On the other hand, S288c originated from a strain isolated from a rotten fig near California (Mortimer and Johnston, 1986; Wei et al., 2007). YJM789 contains about 60,000 SNPs and unique open reading frames (ORFs) with respect to S288c as the reference genome leading to differences in phenotypes and protein polymorphisms. For example, YJM789 is flocculant and can grow under high-temperature conditions (Steinmetz et al., 2002). S288c has no flocculence, minimal colony morphology switching, and does not necessarily grow well in high temperatures (Mortimer and Johnston, 1986). The genetic difference between YJM789 and S288c translates to its phenotypic difference giving one advantage over the other depending on the stressor it's exposed to. 


\section{MCHM SPILL IN WEST VIRGINIA}

In January 2014, large amounts of crude chemical primarily containing MCHM spilled from a storage tank into the Elk River near Charleston, West Virginia, contaminating the local water supply of at least 300,000 residents. The spill prompted a state emergency declaration, and many residents reported having symptoms like mild rashes, gastrointestinal and respiratory issues (Manuel John, 2014; Thomasson et al., 2017). MCHM is commonly used as a frothing agent for cleaning fine coal by separating burnable fossil fuel from other impurities (Jeter et al., 2016). This acyclic primary alcohol exists as two isomers and is known to not degrade easily due to its relatively low reactivity (Foreman et al., 2015). The trans isomer was detectable due to its much more intense 'sweet licorice' odor (L. Gallagher et al., 2015).

The Centers for Disease Control and Prevention released a temporary health advisory following the spill, advising residents not to consume the contaminated water with MCHM levels higher than $1 \mathrm{ppm}$ until further toxicology reports were released (2019). The level of maximum exposure of $\mathrm{MCHM}$ that reached affected homes was approximately $2.6 \mathrm{ppm}$, and the concentration of the chemical continued declining several days after the spill (Weidhaas et al., 2017). By January 19, 2014, all 'do not use' water order was lifted in all areas affected by the spill (Paustenbach et al., 2015).

\section{MCHM AS A HYDROTROPE}

Previous research has shown that MCHM acts as a hydrotrope by altering membrane dynamics and changing how cells uptake nutrients and utilize nutrients (Pupo et al., 2020). Hydrotropes are compounds that, at high enough concentration, possess the ability to alter the solubility of organic solvents in aqueous environments by inducing liquid-liquid phase 
condensates (Subbarao et al., 2012). LLPS push molecules, including organic compounds and proteins, into different conformation states and solubility (Alberti et al., 2019). As we now know, proteins can exist as condensates or liquid droplets that remain separated from the surrounding liquid. As liquid condensates, they behave just like any other liquid molecule by flowing and fusing with other condensates found in the same solubility state (Hahn, 2018).

MCHM also contains a hydrophilic part and a hydrophobic part with structures similar to that of a surfactant (Hopkins Hatzopoulos et al., 2011). Due to their unique characteristics, hydrotropes are widely used for drug solubilization, liquid-liquid separation, and even in the personal care product industry as extraction agents for fragrances (Subbarao et al., 2012). MCHM, in particular, is composed of a saturated hexane ring with a methyl group and a methanol group at opposite carbons, which gives it its hydrotropic nature.

Since the spill, many studies have focused on the toxicological effects of MCHM on organisms, including mammals, in terms of developmental changes and viability. The toxicological effects of MCHM and its metabolites in both yeast and human cells found that cells exposed to MCHM showed increased expression of proteins associated with transmembrane transporters (Lan et al., 2015). Cells exposed to MCHM metabolites, on the other hand, induced proteins associated with oxidative stress and antioxidant activities (Lan et al., 2015).

Initial transcriptomic analysis in yeast showed MCHM had a profound effect on diverse biochemical pathways, including phospholipid biosynthesis (Pupo et al., 2019a), and amino acid metabolism (Pupo et al., 2020). MCHM was found to affect ribosome biogenesis, which 
causes the depletion of protein production, leading to amino acid accumulation (Pupo et al., 2019a). Rather than focus on a single pathway, we explored a novel explanation for MCHM's mode of action. Based on the molecular structure, we hypothesized that MCHM is a hydrotrope changing the composition of liquid condensates by altering the liquid-liquid phase separation. In vivo, this is demonstrated by observing the liquid-like fusion of GFP proteins. However, we did not know which protein could be changed, so we first determined if MCHM can act as a hydrotrope in vitro (Gallagher et al., 2020; Pupo et al., 2020). In cells, hydrotropes such as ATP and RNA are known to prevent protein aggregation, and it comes as no surprise that MCHM behaves the same way. Although not as potent a hydrotrope as ATP, MCHM has the ability to significantly reduce protein aggregation resulting in increased transport across the cell membrane (Pupo et al., 2020). Protein aggregation is known to cause protein inactivation and plays a role in several neurodegenerative diseases such as Alzheimer's and Parkinson's (Aguzzi and O'Connor, 2010). Because ATP and RNA have other roles in the cell and are especially labile, altering their levels would lead to pleiotropic effects. While using MCHM as a synthetic hydrotrope, the role of LLPS can be investigated.

\section{MEDIATOR, A COMPLEX INVOLVED IN TRANSCRIPTION REGULATION}

The expression of most RNA polymerase II (pol II) transcripts which include non-coding RNA genes and all protein-coding genes, is controlled by RNA pol II. However, transcription factors (TFs) do not interact directly with either general transcription factors or RNA pol II, but rather through a multi-subunit complex known as the Mediator (Thomas and Chiang, 2006). 
Being part of the pre-initiation complex, the Mediator is responsible for relaying signals from DNA-bound TFs directly to RNA pol II (Allen and Taatjes, 2015; Poss et al., 2013). This highly conserved complex comprises 4 modules: the head, middle, tail, and kinase domains with about 25 subunits in S. cerevisiae and 26 subunits for humans (Liu et al., 2001; Sato et al., 2003). The human Mediator complex lacks the subunit Med9 and Med19 but instead contains the subunit Med30 (Cevher et al., 2014). In yeast, the head interacts with RNA pol II's C-terminal domain and general TFs, while the middle module is associated with cyclindependent kinases (CDKs). On the other hand, the tail binds to regulatory factors such as stress response regulators (Verger et al., 2019).

Besides its fairly large size and functional versatility, the Mediator is unique because its subunit composition can vary; subunits can be added or lost to facilitate an optimum biological function. Mass spectrometry analyses that have successfully isolated the complex and found that most often times endogenous Mediators tend to lack specific subunits (Taatjes and Tjian, 2004). As a result, some subunits are often either over or underrepresented significantly in mammalian Mediator complexes.

\section{MED15 AND ITS INTERACTION WITH STRESS RESPONSE TRANSCRIPTION FACTORS}

Med15, also known as Gal11 in Saccharomyces cerevisiae, is a 120kDA subunit found in the tail module of the Mediator complex (Poss et al., 2013). Med15 has a unique amino acid sequence that differs depending on the strain it originates from. Med15 isolated from S288c is $16 \%$ glutamine and $11 \%$ asparagine, while Med15 from YJM789 is about $17 \%$ glutamine and $11 \%$ asparagine. The human Med15 differs slightly in its glutamine composition and overall length when compared to yeast orthologs. It consists of $20 \%$ glutamine and is about 27\% shorter (Gallagher et al., 2020; Harper and Taatjes, 2018). 
One of the many unique features of Med15 is that it contains a kinase inducible (KIX) domain at the $\mathrm{N}$-terminal, which serves as a docking site for the formation of heterodimers between the coactivator and specific transcription factors (Tuttle et al., 2018; Thakur et al., 2014). The KIX domain is a highly conserved three-helix bundle and was discovered to have significant similarity between diverse organisms at sequence, structural and functional levels (Thakur et al., 2014; Jedidi et al., 2010). Besides the KIX domain, the other unique feature of Med15 is that it contains two regions of polyglutamine (polyQ) tracts that are separated by a polyglutamine-alanine (polyQA) tract. Between each of these tracts are activator-binding domains (ABDs) (Herbig et al., 2010). All these regions, including the KIX domain, interact with transcription factors through multiple fuzzy domain sites that are intrinsically disordered. (Tuttle et al., 2018; Jedidi et al., 2010). For example, Gcn4 interacts with Med15 by forming a dynamic protein-protein interface via those fuzzy domains (Herbig et al., 2010; Brzovic et al., 2011). The fuzzy domain mechanism allows weak and low-affinity interactions to combine to ultimately produce a biologically functional complex with higher specificity and stronger affinity (Tuttle et al., 2018; Warfield et al., 2014). We posit that these fuzzy domains, based on their interactions, are the protein condensates when cells are exposed to a hydrotrope like MCHM. At the C-terminal end of Med15 is the Mediator activation/association domain (MAD), which contains multiple phosphorylation sites and is found to be heavily phosphorylated (Albuquerque et al., 2008; Holt et al., 2009).

Due to its interesting structure and features, the genetic variations of Med15, especially those within the polyQ tracts, were expected to be diverse. The polyQ tracts of Med15 from five genetically diverse yeast had between 12 to 25 glutamines in polyQI and between 18 
and 27 glutamines in polyQII (ref). It was hypothesized that these polyQ variations are responsible for the phenotypic variations seen in previous studies involving different growth conditions. Because polyQ tracts are vital in forming interactions with transcription factors, including those involved in stress responses, genetic variations of these tracts are hypothesized to result in a diverse response when exposed to stressors such as MCHM and 4-NQO.

\section{REFERENCES}

(2019). West Virginia 2014 | CDC Emergency Preparedness \& Response. Accessed from https://emergency.cdc.gov/chemical/MCHM/westvirginia2014/

Aguzzi, A., and O'Connor, T. (2010). Protein aggregation diseases: pathogenicity and therapeutic perspectives. Nature Reviews Drug Discovery 9, 237-248.

Alberti, S., Gladfelter, A., and Mittag, T. (2019). Considerations and challenges in studying liquid-liquid phase separation and biomolecular condensates. Cell 176, 419-434.

Albuquerque, C.P., Smolka, M.B., Payne, S.H., Bafna, V., Eng, J., and Zhou, H. (2008). A Multidimensional Chromatography Technology for In-depth Phosphoproteome Analysis. Mol Cell Proteomics 7, 1389-1396.

Allen, B.L., and Taatjes, D.J. (2015). The Mediator complex: a central integrator of transcription. Nat Rev Mol Cell Biol 16, 155-166.

Botstein, D., Chervitz, S.A., and Cherry, J.M. (1997). Yeast as a Model Organism. Science 277, 1259-1260. 
Botstein, D., and Fink, G.R. (2011). Yeast: An Experimental Organism for 21st Century Biology. Genetics 189, 695-704.

Brzovic, P.S., Heikaus, C.C., Kisselev, L., Vernon, R., Herbig, E., Pacheco, D., Warfield, L., Littlefield, P., Baker, D., Klevit, R.E., et al. (2011). The acidic transcription activator Gcn4 binds the Mediator subunit Gal11/Med15 using a simple protein interface forming a fuzzy complex. Mol Cell 44, 942-953.

Cevher, M.A., Shi, Y., Li, D., Chait, B.T., Malik, S., and Roeder, R.G. (2014). Reconstitution of active human core Mediator complex reveals a critical role of the MED14 subunit. Nature Structural \& Molecular Biology 21, 1028-1034.

Duina, A.A., Miller, M.E., and Keeney, J.B. (2014). Budding Yeast for Budding Geneticists: A Primer on the Saccharomyces cerevisiae Model System. Genetics 197, 33-48.

Engel, S.R., and Cherry, J.M. (2013). The new modern era of yeast genomics: community sequencing and the resulting annotation of multiple Saccharomyces cerevisiae strains at the Saccharomyces Genome Database. Database (Oxford) 2013.

Foreman, W.T., Rose, D.L., Chambers, D.B., Crain, A.S., Murtagh, L.K., Thakellapalli, H., and Wang, K.K. (2015). Determination of (4-methylcyclohexyl)methanol isomers by heated purge-and-trap GC/MS in water samples from the 2014 Elk River, West Virginia, chemical spill. Chemosphere 131, 217-224.

Gallagher, D.L., Phetxumphou, K., Smiley, E., and Dietrich, A.M. (2015). Tale of Two Isomers: Complexities of Human Odor Perception for cis- and trans-4-Methylcyclohexane Methanol from the Chemical Spill in West Virginia. Environ. Sci. Technol. 49, 1319-1327. 
Gallagher, J.E.G., Ser, S.L., Ayers, M.C., Nassif, C., and Pupo, A. (2020). The Polymorphic PolyQ Tail Protein of the Mediator Complex, Med15, Regulates the Variable Response to Diverse Stresses. International Journal of Molecular Sciences 21, 1894.

Hahn, S. (2018). Phase Separation, Protein Disorder, and Enhancer Function. Cell 175, 17231725.

Harper, T.M., and Taatjes, D.J. (2018). The complex structure and function of Mediator. J Biol Chem 293, 13778-13785.

Herbig, E., Warfield, L., Fish, L., Fishburn, J., Knutson, B.A., Moorefield, B., Pacheco, D., and Hahn, S. (2010). Mechanism of Mediator Recruitment by Tandem Gcn4 Activation Domains and Three Gal11 Activator-Binding Domains. Mol Cell Biol 30, 2376-2390.

Holt, L.J., Tuch, B.B., Villén, J., Johnson, A.D., Gygi, S.P., and Morgan, D.O. (2009). Global analysis of Cdk1 substrate phosphorylation sites provides insights into evolution. Science $325,1682$.

Hopkins Hatzopoulos, M., Eastoe, J., Dowding, P.J., Rogers, S.E., Heenan, R., and Dyer, R. (2011). Are Hydrotropes Distinct from Surfactants? Langmuir 27, 12346-12353.

Jedidi, I., Zhang, F., Qiu, H., Stahl, S.J., Palmer, I., Kaufman, J.D., Nadaud, P.S., Mukherjee, S., Wingfield, P.T., Jaroniec, C.P., et al. (2010). Activator Gcn4 employs multiple segments of Med15/Gal11, including the KIX domain, to recruit mediator to target genes in vivo. J Biol Chem 285, 2438-2455.

Jeter, T.S., Sarver, E.A., McNair, H.M., and Rezaee, M. (2016). 4-MCHM sorption to and desorption from granular activated carbon and raw coal. Chemosphere 157, 160-165. 
Lan, J., Hu, M., Gao, C., Alshawabkeh, A., and Gu, A.Z. (2015). Toxicity Assessment of 4Methyl-1-cyclohexanemethanol and Its Metabolites in Response to a Recent Chemical Spill in West Virginia, USA. Environ Sci Technol 49, 6284-6293

Liu, W., Li, L., Ye, H., Chen, H., Shen, W., Zhong, Y., Tian, T., and He, H. (2017). From Saccharomyces cerevisiae to human: The important gene co-expression modules. Biomed Rep 7, 153-158.

Liu, Y., Ranish, J.A., Aebersold, R., and Hahn, S. (2001). Yeast Nuclear Extract Contains Two Major Forms of RNA Polymerase II Mediator Complexes * Journal of Biological Chemistry $276,7169-7175$

Manuel John (2014). Crisis and Emergency Risk Communication: Lessons from the Elk River Spill. Environmental Health Perspectives 122, A214-A219.

Mortimer, R.K., and Johnston, J.R. (1986). Genealogy of Principal Strains of the Yeast Genetic Stock Center. Genetics 113, 35-43.

Paustenbach, D.J., Winans, B., Novick, R.M., and Green, S.M. (2015). The toxicity of crude 4methylcyclohexanemethanol (MCHM): review of experimental data and results of predictive models for its constituents and a putative metabolite. Crit Rev Toxicol 45 Supp/ 2, 1-55.

Poss, Z.C., Ebmeier, C.C., and Taatjes, D.J. (2013). The Mediator complex and transcription regulation. Critical Reviews in Biochemistry and Molecular Biology 48, 575-608.

Pupo, A., Ku, K.M., and Gallagher, J.E.G. (2019a). Effects of MCHM on yeast metabolism. PLoS One 14. 
Pupo, A., Ayers, M.C., Sherman, Z.N., Vance, R.J., Cumming, J.R., and Gallagher, J.E.G.

(2020). MCHM Acts as a Hydrotrope, Altering the Balance of Metals in Yeast. Biol Trace Elem Res 195, 260-271.

Sato, S., Tomomori-Sato, C., Banks, C.A.S., Sorokina, I., Parmely, T.J., Kong, S.E., Jin, J., Cai, Y., Lane, W.S., Brower, C.S., et al. (2003). Identification of Mammalian Mediator Subunits with Similarities to Yeast Mediator Subunits Srb5, Srb6, Med11, and Rox3 * 210. Journal of Biological Chemistry 278, 15123-15127.

Steinmetz, L.M., Sinha, H., Richards, D.R., Spiegelman, J.I., Oefner, P.J., McCusker, J.H., and Davis, R.W. (2002). Dissecting the architecture of a quantitative trait locus in yeast. Nature $416,326-330$.

Subbarao, C., Chakravarthy, I., a V S L, B., and Prasad, K. (2012). Functions of Hydrotropes in Solutions. Chemical Engineering \& Technology 35, 225-237.

Taatjes, D.J., and Tjian, R. (2004). Structure and function of CRSP/Med2; a promoterselective transcriptional coactivator complex. Mol Cell 14, 675-683.

Tawfik, O.W., Papasian, C.J., Dixon, A.Y., and Potter, L.M. (1989). Saccharomyces cerevisiae pneumonia in a patient with acquired immune deficiency syndrome. J Clin Microbiol 27, $1689-1691$.

Thakur, J.K., Yadav, A., and Yadav, G. (2014). Molecular recognition by the KIX domain and its role in gene regulation. Nucleic Acids Res 42, 2112-2125.

Thomas, M.C., and Chiang, C.-M. (2006). The General Transcription Machinery and General Cofactors. Critical Reviews in Biochemistry and Molecular Biology 41, 105-178. 
Thomasson, E.D., Scharman, E., Fechter-Leggett, E., Bixler, D., Ibrahim, S., Duncan, M.A., Hsu, J., Scott, M., Wilson, S., Haddy, L., et al. (2017). Acute Health Effects After the Elk River Chemical Spill, West Virginia, January 2014. Public Health Rep 132, 196-202.

Tuttle, L.M., Pacheco, D., Warfield, L., Luo, J., Ranish, J., Hahn, S., and Klevit, R.E. (2018). Gcn4-Mediator Specificity Is Mediated by a Large and Dynamic Fuzzy Protein-Protein Complex. Cell Reports 22, 3251-3264.

Verger, A., Monté, D., and Villeret, V. (2019). Twenty years of Mediator complex structural studies. Biochemical Society Transactions 47, 399-410.

Warfield, L., Tuttle, L.M., Pacheco, D., Klevit, R.E., and Hahn, S. (2014). A sequence-specific transcription activator motif and powerful synthetic variants that bind Mediator using a fuzzy protein interface. PNAS 111, E3506-E3513.

Wei, W., McCusker, J.H., Hyman, R.W., Jones, T., Ning, Y., Cao, Z., Gu, Z., Bruno, D., Miranda, M., Nguyen, M., et al. (2007). Genome sequencing and comparative analysis of Saccharomyces cerevisiae strain YJM789. Proceedings of the National Academy of Sciences $104,12825-12830$.

Weidhaas, J., Lin, L.-S., and Buzby, K. (2017). A case study for orphaned chemicals: 4methylcyclohexanemethanol (MCHM) and propylene glycol phenyl ether (PPH) in riverine sediment and water treatment processes. Science of The Total Environment 574, 13961404. 


\section{CHAPTER 3: THE POLYMORPHIC POLYQ TAIL PROTEIN OF THE MEDIATOR COMPLEX, MED15, REGULATES VARIABLE RESPONSE TO DIVERSE STRESSES}

Jennifer E.G. Gallagher*, Suk Lan Ser, Michael C. Ayers, Casey Nassif, and Amaury Pupo

Paper published in International Journal of Molecular Sciences on 10 March 2020

Gallagher, J.E.G., Ser, S.L., Ayers, M.C., Nassif, C., and Pupo, A. (2020). The Polymorphic PolyQ Tail Protein of the Mediator Complex, Med15, Regulates the Variable Response to Diverse Stresses. International Journal of Molecular Sciences 21, 1894.

*corresponding author

Jennifer Gallagher

53 Campus Drive, LSB 3140

West Virginia University

Morgantown, WV 26506

jegallagher@mail.wvu.edu

Running title: Polymorphic Med15 and stress in yeast

Keywords: Mediator, stress, MCHM, Med15, Snf1, polyQ, protein chaperone, master variator, intrinsically disordered regions, yeast, hydrotrope, transcription factors, Myc tag, inorganic phosphate 


\section{Abstract}

The Mediator is composed of multiple subunits conserved from yeast to humans and plays a central role in transcription. The tail components are not required for basal transcription but are required for response to different stresses. While some stresses are familiar such as heat, desiccation, and starvation, others are exotic, yet yeast can elicit a successful stress response. $\mathrm{MCHM}$ is a hydrotrope that induces growth arrest in yeast. We found that a naturally occurring variation in the Med15 allele, a component of the Mediator tail, altered the stress response to many chemicals in addition to MCHM. Med15 contains two polyglutamine repeats (polyQ) of variable lengths that change the gene expression of diverse pathways. Med15 protein existed in multiple isoforms and its stability was dependent on Ydj1, a protein chaperone. The protein level of the Med15 with longer polyQ tracts was lower and turned over faster than the allele with shorter polyQ repeats. MCHM sensitivity via variation of Med15 was regulated by Snf1 in a Myc tag dependent manner. Tagging Med15 with Myc altered its function in response to stress. Genetic variation in transcriptional regulators magnifies genetic differences in response to environmental changes. These polymorphic control genes are master variators.

\section{Background}

Changing the transcriptional landscape is a key step in reorganizing cellular processes in response to stress. RNA polymerase II (pol II) transcription is regulated in a stress-specific manner by multiple post-translational modifications and a host of transcription factors (TFs). These transcription factors do not interact directly with pol II and general transcription factors (GTFs), together called the pre-initiation complex, but through a multi-protein 
complex called the Mediator. The Mediator itself is composed of four modules: the head, middle, tail and kinase domains (Figure 1A). The head interacts with pol II and GTFs while the tail interacts with specific TFs (reviewed Verger et al., 2019). The tail is composed of Med2, Med3 (Pgd1), Med5 (Nut1), Med15 (Gal11) and Med16 (Sin4) and the C-terminal end of Med14 connects the tail with the middle of the Mediator complex (Figure 1B) (Robinson et al., 2015; Tsai et al., 2014). The tail is the most diverged module between species, and binding of TF changes the conformation (Bourbon, 2008). The Mediator is essential for regulating the expression of most RNA pol II transcripts (Poss et al., 2013). Med15, a component of the Mediator tail complex directly interacts with various transcription factors and has several known phosphorylations that may regulate its function. In yeast, Med15 regulates Oaf1 (fatty acid level sensor), Pdr1 (a transcription factor that regulates pleiotropic drug response), Ino2 (transcription factor involved in inositol response), and Pho4 (basic helix-loop-helix transcription factor of the Myc-family) to name a few (Miller et al., 2012). Pho4 is a regulatory factor involved in phosphate metabolism and activates other phosphate regulatory genes such as $\mathrm{PHO5}$ under low phosphate conditions (Korber and Barbaric, 2014). Being part of the Myc-family, the DNA binding domain of Pho4 has sequence similarity with various mammalian transcription factors including Myc, which recognizes the palindromic sequence 5'- CACGTG-3' of basic helix-loop-helix motifs (bHLH) (Shao et al., 1998). Chimeras of Pho4-Gal4 in which the bHLH region of the transcription factor was replaced with c-myc remain fully functional (Shao et al., 1996). 


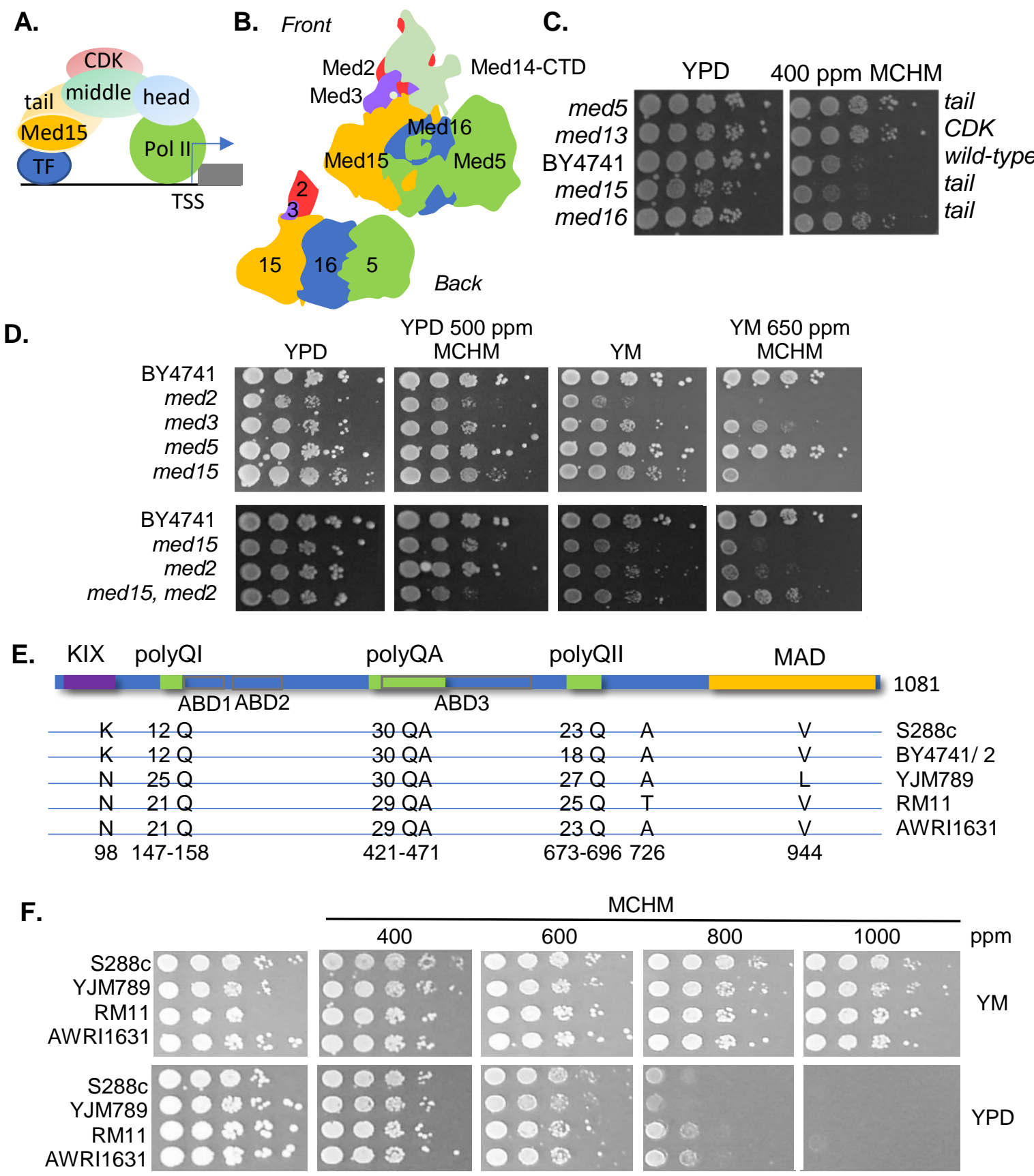

Figure 1 Role of Mediator tail in response to MCHM (A) Schematic of the Mediator complex. Med15 as part of the tail subcomplex directly interacts with transcription factors (TF). The middle of the Mediator complex tethers the CDK (cyclin-dependent kinase). The head directly interacts with RNA polymerase II (Pol II) at promoter regions to initiate transcription at transcriptional start sites (TSS) of genes (gray box). (B) Representation of protein components of the Mediator tail based on structures and modeling ((Robinson et al., 2015). Med2 (red), Med14-CTD (light green), Med3 (purple), Med15 (orange), Med16 (blue) and Med5 (green) comprise the tail of the Mediator complex. From the back view, Med5, Med16, Med15, Med3 and Med2 (in order from farthest to closest to the rest of the Mediator complex) associated with Med14 (not pictured here). (C) Growth assays of yeast with different components of the Mediator knocked out in BY4741 grown with and without 400 ppm MCHM in YPD. (D) Growth assays of yeast with different components of the Mediator tail knocked out in BY4741 grown with and without 500 ppm MCHM or 650 ppm 
in YPD or YM+HULM respectively. (E) Schematic of Med15 protein. Above the blue line are polymorphic domains including the KIX domain, polyglutamine domain I (polyQI), polyglutamine/ alanine domain (polyQA), polyglutamine domain II (polyQII) and the Mediator activation/ association domain (MAD). Under the blue line are the fuzzy domains represented as ABD1-3 (activator-binding domains) in gray outlined boxes ((Brzovic et al., 2011; Herbig et al., 2010). The Med15 polymorphic amino acids are diagramed below from five genetically diverse yeast. Amino acid numbers are based on S288c. (F) Growth assays of genetically diverse yeast strains in the presence of $\mathrm{MCHM}$ on different growth media with increasing concentrations of MCHM. Yeast were spotted in ten-fold dilutions onto minimal media supplemented with lysine (YM), or rich media (YPD). RM11, S288c (GSY147), AWRI1631 are MATa prototrophs while YJM789 is a MATalpha lys2 strain. (Contributed by Jen Gallagher: A,B,D and E). (Contributed by Casey Nassif: $C$ and F).

Overexpression of Med15 causes protein aggregation (Alberti et al., 2009), presumably via the polyQ and polyQA regions as this region alone aggregates in response to hydrogen peroxide (Zhu et al., 2015). Overexpression of the first polyQ and polyQA of Med15 reduces cell growth in unstressed cells and salt exposed yeast but rescues growth in the presence of rapamycin (Zhu et al., 2015). Full-length Med15 also forms cytosolic foci in yeast exposed to hydrogen peroxide (Zhu et al., 2015). The pathogenic effects of polyQ proteins were uncovered when the causative mutation for Huntington's disease was discovered (Baxendale et al., 1993). Huntington's disease causes progressive neurodegeneration in people who inherit a single copy of HTT with the polyQ expansion inducing protein aggregation (reviewed (Landles and Bates, 2004)). Aggregation of polyQ expansion proteins in yeast can be reduced by overexpression of chaperone proteins (Krobitsch and Lindquist, 1999). Ydj1 is a highly expressed general type I Hsp40 protein (J-type) chaperone that localizes to the mitochondria, cytoplasm, and nucleus. Yeast lacking Ydj1 function are sensitive to multiple classes of chemicals (Gillies et al., 2012). Hsp40 proteins work with Hsp70 to refold misfolded proteins or target them for degradation. They also have roles in translation, translocation across membranes and conformation changes induced by amyloid fibrils. Overexpression of Ydj1 can cure prions (Hines et al., 2011). Prions are a group of 
proteins that not only aggregate but also can induce the aggregation of natively folded proteins. Prions can cause contagious neurodegenerative diseases in humans and switches in the prion state provide epigenetic plasticity in phenotypic response to stresses by regulating the enzymatic function (Alberti et al., 2009). Overlapping the polyQ domains are the intrinsically disordered regions (IDR) that form fuzzy interactions with TFs, in particular, Gcn4 (Brzovic et al., 2011b; Pacheco et al., 2018; Tuttle et al., 2018b; Warfield et al., 2014b). An N-terminal fragment of Med15 containing the first polyQ and the polyQA domain will form liquid phase condensates, also known as liquid-liquid phase separation, with Gcn4 at low concentrations in vitro (Boija et al., 2018). These condensates are dynamic and behave like a liquid (reviewed (Hahn, 2018b)). A mutant of Gcn4, which does not form liquid droplet (phase separation) condensates with Med15, no longer activates transcription (Boija et al., 2018). The transition from single phase to liquid phase droplet increases the local concentration of factors by forming non-membrane bound compartments that flow and fuse with surface tension (reviewed in (Alberti et al., 2019)). Liquid phase droplets can be induced by chemicals and act as protein concentrators. IDR interactions may be a more general mechanism to increase the local concentration of proteins within liquid droplets, changing protein conformations, and adding complexity regulating cellular metabolism and environmental responses.

In 2014, there was a large spill of MCHM (4-methylcyclohexane methanol), a coal-cleaning chemical, into the Elk River in West Virginia, contaminating the drinking water of 300,000 people (Hsu et al., 2017). Many of those people suffered from various significant illnesses including mild skin irritation, respiratory and gastrointestinal symptoms (Thomasson et al., 2017). Hydrotropes increase the solubility of organic compounds by inducing liquid phase 
condensates. Currently, hydrotropes are not considered detergents, and detergents function at lower concentrations to solubilize compounds. MCHM acts as a hydrotrope in vitro and preventing protein aggregations (Pupo et al., 2019b). In contrast to ATP (Hayes et al., 2018; Kang et al., 2018; Patel et al., 2017) and RNA (Lin et al., 2015) which are easily metabolized by cells, MCHM can serve as a model hydrotrope to study the effect of hydrotropes on biological systems. RNA and ATP can be rapidly turned over while MCHM is a cyclic hydrocarbon with saturated bonds that are difficult to break. MCHM is an exotic hydrotrope, and yeast would not have been exposed to MCHM. Exposure to MCHM induced growth inhibition in yeast by changing a wide range of biochemical pathways including the ionome (Pupo et al., 2019b) and amino acids (Pupo et al., 2019c). The Mediator binds upstream of many genes across pathways, including stress-responsive genes. Numerous studies have explored the role of Med15 via knockouts on microarrays and later RNAseq. Removing the entire coding region not only removes the function of a protein but also alters the structure of complexes containing that protein. Gene knockouts are rarely found in nature, while indels, copy number variation, and SNPs are the most common mutations. By assessing the role of a naturally variable protein, the integrity of the Mediator is maintained and the specific function of Med15 can be addressed in response to hydrotropic chemicals, such as MCHM.

AMP kinases regulate ATP levels, and the yeast ortholog is a heterotrimeric complex called SNF1 (reviewed in (Hedbacker and Carlson, 2008)). In glucose limitation or other stresses, Snf1, the catalytically active kinase in SNF1 complex, is phosphorylated on T210 by Tos3, Eml1, or Sak1, Upstream Activating Kinases (USAKs, reviewed in (Hedbacker and Carlson, 2008)). The protein phosphatase 1 (PP1) negatively regulates SNF1 by dephosphorylation of 
Snf1 by Glc7 in the presence of glucose. Reg1 regulates the activity of PP1, and in a reg1 mutant, SNF1 complex is constitutively active because of the lack of dephosphorylation. Snf1 itself forms liquid droplets in the nuclear vacuole junction (reviewed (Simpson-Lavy and Kupiec, 2018)). Myc, a commonly used epitope tag derived from transcription factor, cMyc, is phosphorylated by SNF1, the yeast homolog of AMP kinase, in vitro (M Schmidt, personal communication) and Snf1 physically associates with the Mediator complex (Uthe et al., 2017). SNF1 regulates multiple nutrient-sensing pathways and is important for response to numerous and diverse chemicals.

$\mathrm{MCHM}$ is an exotic hydrotrope that changes the solubility and presumably the structure of proteins. The initial goal of this research was to characterize how a single polymorphic protein, Med15, regulates gene expression in response to a hydrotrope. As the altered state of protein conformation/ phase (single verse liquid) are coming to light, the highly variable Med15 was further characterized. Polymorphic transcriptional regulators allow a small genetic variation to have a large impact on phenotypic variation. A single polymorphism of threonine to isoleucine removed a potential phosphorylation site in Yrr1, a transcription factor, which confers $4 \mathrm{NQO}$ sensitivity but has the benefit of increased respiration (Gallagher et al., 2014; Rong-Mullins et al., 2018). These polymorphic proteins are termed master variators (Gallagher et al., 2014). MCHM is a hydrotrope that increases protein solubility (Pupo et al., 2019b), and a truncated version Med15, containing polyQI and polyQA can exist as liquid droplets in vitro with TFs (Boija et al., 2018). Master variators magnify the effect of genetic variation on phenotypic plasticity. Genetic variation of Med15 regulated cellular response to $\mathrm{MCHM}$, and in the process, we uncovered how a tag of Myc 
on Med15 altered the function of the Mediator in conjunction with SNF1 to regulate the cellular response to not only MCHM but to other diverse stressors.

\section{Results}

The growth of yeast with different components of the Mediator complex knocked out was tested in the response to MCHM (Figure 1C). As the tail directly interacts with the TFs, med15, med16, and med5 knockouts were tested and med13 from the CDK-associated module? was chosen because it is on the other side of the complex from the tail. Mutants in med5, med13, and med16 grew better in response to MCHM than the parental strain, BY4741, while the growth of the med15 mutant was inhibited after two days of growth. Med16 and Med5 are at the distal end of the mediator complex? while Med2 and Med3 are on the other side of Med15 and closer to the middle module. The med 2 and med15 mutants were also sensitive to MCHM in YPD and more so in YM (yeast minimal media with necessary supplements added to cover the auxotrophies, Figure 1D). We tested a med15, med2 double mutant, which suppressed the MCHM sensitivity on YM and enhanced sensitivity in YPD. MCHM is a very volatile chemical with a narrow dosage range. Hence there is much plate to plate variation and only strains on the same plate can be directly compared to each other.

Med15 has a curious amino acid sequence (Figure 1E and reviewed (Cooper and Fassler, 2019)). Med15 from a common lab strain S288c is $16 \%$ glutamines and $11 \%$ asparagines. Across eukaryotic proteomes, the average $\mathrm{Q}$ content is $4 \%$ and $\mathrm{N}$ content is $5 \%$ (Michelitsch and Weissman, 2000). The proportion of $\mathrm{Q} / \mathrm{N}$ amino acids is higher than expected based on the distribution of amino acids, and thermophilic organisms do not have this category of 
proteins (Michelitsch and Weissman, 2000). Human Med15 is $20 \%$ glutamines and is $27 \%$ shorter compared to the yeast ortholog (Supplemental Figure S1). While $47 \%$ of human orthologs tested can complement yeast knockouts, the percentage decreases for transcription factors and other proteins that associate with DNA (Kachroo et al., 2015). Between species, the C-terminal end of Med15 is highly divergent and required for the association to the Mediator complex, via the Mediator activation/association domain (MAD). MAD is heavily phosphorylated but the exact roles of these phosphorylations have not been determined (Albuquerque et al., 2008; Holt et al., 2009; Soulard et al., 2010; Swaney et al., 2013). Between polyQI and polyQII and partially overlapping with the polyQA tract are three ABD (Activator Binding Domains) regions (Pacheco et al., 2018). The ABDs and KIX domain form fuzzy interactions with TFs (Tuttle et al., 2018; Warfield et al., 2014). The unusual structure of Med15 leads us to investigate whether Med15 from other strains had genetic variation in the polyQ tracts. Med15 from five genetically diverse yeast had between 12 and 25 Qs in the polyQI and between 18 and 27 Qs in polyQII. The polyQA only differed by one less QA repeat in RM11 and AWRI1631 Med15 alleles. There were three other non-synonymous SNPs: K98N, A726T, and V944L using S288c allele numbering. These strains were then tested on increasing concentrations of MCHM in YPD and YM (Figure 1F). There was a mild decrease in growth in the strains in YM at the highest concentration of $1000 \mathrm{ppm}$ MCHM, which is the limit of solubility of MCHM in media, but there was no difference detected across these strains. These strains are prototrophs and are more robust than BY4741 (Figure S2A). Growth was slowed at 800 ppm MCHM in YPD with YJM789 being the most sensitive.

YJM789 and BY4741 were selected for further study because their alleles of Med15 represent the range of variation in polyQ lengths, differences in $\mathrm{MCHM}$ resistance and 
available genetic markers (Figure 2SA). Reciprocal hemizygosity assays were carried out. MED15 was knocked out in haploid parent strains and diploids selected. Both the MED15 ${ }^{Y J M 789} / \Delta$ and the $M E D 15^{B Y} / \Delta$ diploids were equally sensitive to MCHM (Figure $2 \mathrm{~A}$ ). However, when compared to the homozygous mutant, the hemizygotes were more sensitive. Suggesting there is no impact of the different alleles of Med15 on MCHM response in the context of a hybrid Mediator complex, but Med15 is important possibly as a gene dosage effect with respect to the stoichiometry of the Mediator complex.

The gene dosage could mask allelic differences in the diploid hemizygotes, so to control for this, MED15 was swapped in BY4741 and YJM789 haploid knockouts. MED15 alleles were cloned from yeast which had their MED15 alleles tagged with Myc at the chromosomal location with the KanR marker. Both alleles were expressed under their endogenous promoters from a single-copy plasmid. We did find that the Myc tag on Med15 increased the sensitivity of yeast to MCHM when comparing the reciprocal hemizygotes to the untagged strains. The growth of Myc-tagged hemizygous mutants was inhibited at $550 \mathrm{ppm}$ while the untagged mutants were inhibited at $650 \mathrm{ppm}$ (Figure S2B, Figure 2A). MED15 was knocked out in BY4741 and YJM789 and transformed with the two alleles of Med15-Myc with the empty plasmid as the negative control and were grown in YPD or YM (with MSG as the nitrogen source instead of ammonium sulfate to maintain the selection of the KanR plasmid in minimal media with G418). Wildtype BY4741 grew slower than BY4741 carrying Med15 $2288 \mathrm{C}$-Myc in YPD with low levels of MCHM for two days (Figure 2B row 1 and 4). In these same conditions, there is very little change in the growth of the BY4741 med15

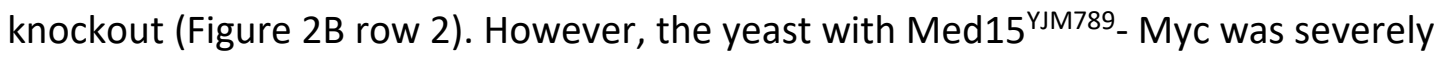
affected by MCHM. Consistent with the growth of the other strains, more MCHM was 
required in YM to slow growth of yeast and there was no difference between the three

alleles of Med15 (row 5, 6, and 8). The med15 knockout grew slower in YM but appeared to be not affected by MCHM when the slow growth of this mutant was also taken into account (Figure 2B row 6). YJM789 growth was not affected by the alleles of Med15-Myc expressed in YPD or YM (Figure 2B row 9, 11, 12, 13, 15, 16). YJM789 med15 mutant grew slower in YM, yet mutant growth was about the same in 400 ppm MCHM in YPD and YM. At 550 and 650 ppm MCHM in YPD, the knockout grew better in YPD than yeast with Med15-Myc but not in YM.

A.

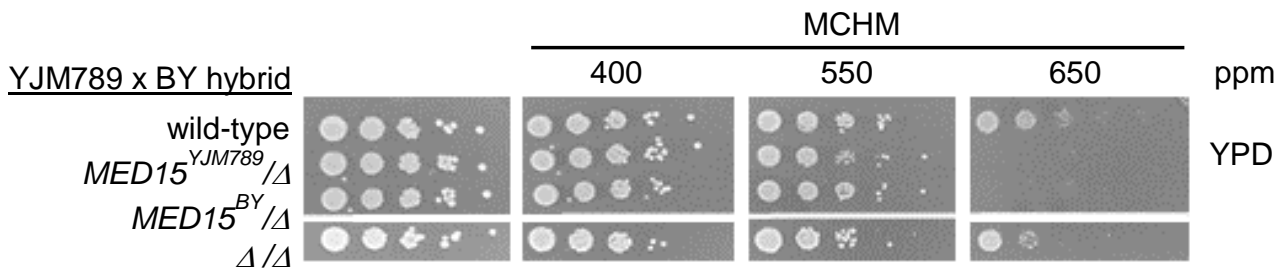

B. $\Delta / \Delta$
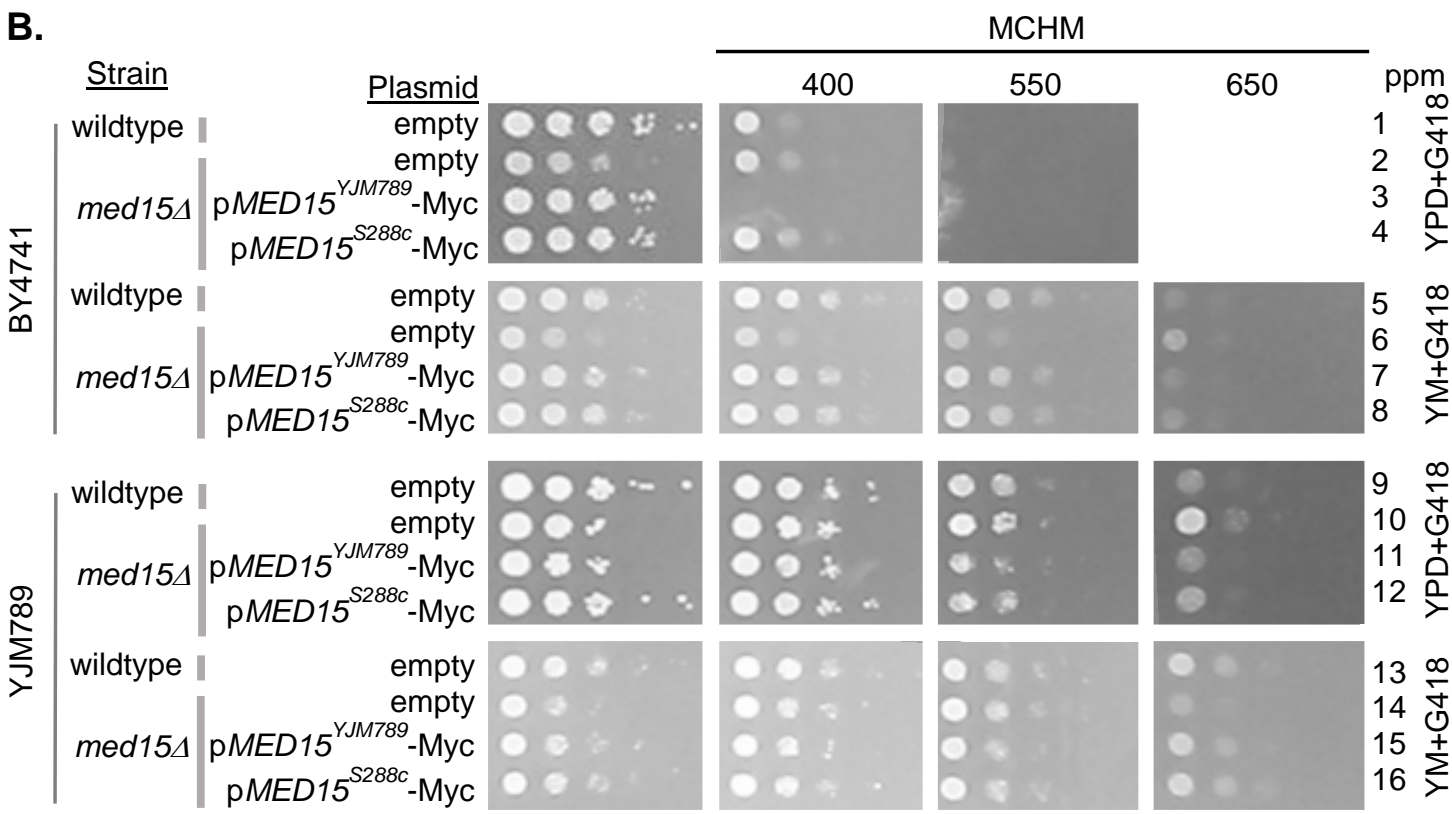

C.

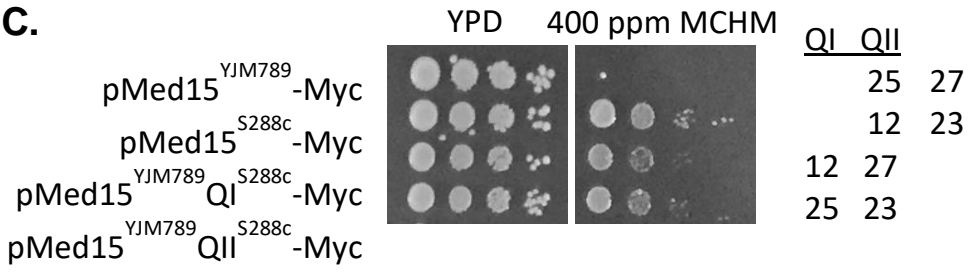

Figure 2 Genetic variation in Med15 contributes to variation in MCHM response. (A) Reciprocal hemizygotes of Med15 in BY4741XYJM789 hybrids were grown on MCHM in YPD. 
Med15 was tagged at the chromosomal locus with $13 x$ Myc at the C-terminal end or knockout with a dominant drug marker in haploid parents. Yeast were then mated, and diploids selected. (B) Med15 allele swap in BY4741 and YJM789 was carried out by cloning Med15-13xMyc with KanR onto pRS316. Med15 plasmids were transformed into wildtype and med15::NatR stains in the BY4741 and YJM789 (YJM789K5a, a MATa prototroph) backgrounds. Plasmids were maintained by growth on YPD with G418. Glutamate (MSG) was used as the nitrogen source in minimal media with histidine, uracil, leucine, and methionine to supplement BY4741 so that G418 would be selective and maintain the plasmid. The empty plasmid is pGS35 (KanR). (C) Growth of BY4741 med15 mutants expressing polyQI and polyQII domain swaps in Med15 $5^{\mathrm{YJM} 789}$-Myc. The length of each polyQ for each allele is noted to the right of the figure. (Contributed by Jen Gallagher).

It is surprising that BY4741 Med15 ${ }^{\mathrm{YJM} 789}-\mathrm{Myc}$ yeast were more sensitive to $\mathrm{MCHM}$ in YPD than the med15 knockout yeast. To test if the Med15 $5^{\mathrm{YJM} 789}$-Myc was a dominant-negative allele, Med15 ${ }^{\mathrm{YJM} 789}-\mathrm{Myc}$ was expressed in wildtype BY4741 with endogenous Med15 ${ }^{\mathrm{BY}}$. Expressing both Med15 $5^{\mathrm{YJM} 789}-\mathrm{Myc}$ and $\mathrm{Med} 15^{\mathrm{BY}}$ in yeast did not change growth in YPD with $\mathrm{MCHM}$, and no difference was noted when compared to yeast with Med15 $5^{\mathrm{S} 288 \mathrm{C}}$-Myc and Med15 ${ }^{\mathrm{BY}}$ in the BY4741 med15 knockout (Figure S2C row 7 and 8). However, yeast expressing both Med15 ${ }^{\mathrm{YJM} 789}-\mathrm{Myc}$ and $\mathrm{Med} 15^{\mathrm{BY}}$ were more sensitive to MCHM in YM with high levels of $\mathrm{MCHM}$ (Figure $\mathrm{S} 2 \mathrm{C}$ row 7 and 8 ). To assess the impact of the variation of each polyQ tract on yeast growth in the presence of MCHM, the polyQ domains from Med15 $1288 \mathrm{c}$ were used to replace the respective domains in Med15 ${ }^{\mathrm{YJM} 789}$. Both poly $\mathrm{Q}^{\mathrm{S} 288 \mathrm{C}}$ swapped alleles improved the growth of the yeast containing Med15 ${ }^{\mathrm{YJM} 789}$ (Figure 2C). Although, each poly $\mathrm{Q}^{\mathrm{S288c}}$ swap partially rescued the growth defect contributed by the Med15 ${ }^{\mathrm{YJM} 789}$ allele. We continued studies with Med15 ${ }^{\mathrm{YJM} 789}$ and Med15 ${ }^{\mathrm{S288c}}$ for comparison.

To determine if the protein levels of Med15 contribute to differences in MCHM sensitivity, protein levels of the cloned alleles Med15-Myc in the allele swapped strains were measured. Med15-Myc proteins were immunoprecipitated because the levels are too low to 
detect by western blot without enrichment. Yeast were grown to mid-log phase in YPD or YM with amino acids supplemented and then shifted to media containing MCHM for 30

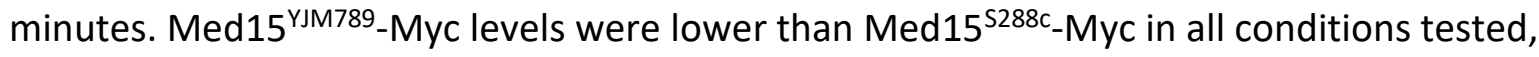
YPD, YM, and with and without MCHM. In general, the levels of both alleles were lower in YM. Med15 ${ }^{\mathrm{YJM} 789}-$ Myc levels also appeared to decrease in YPD with MCHM but the decreased levels did not explain the MCHM sensitivity as the med15 knockout was not as

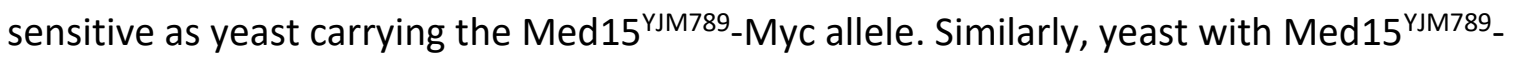

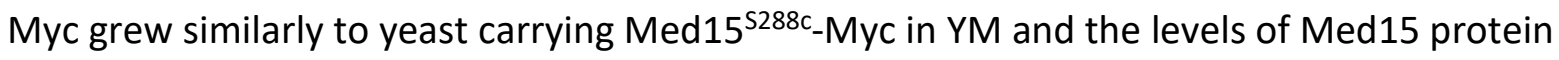
were very different in YM (Figure 3A). It is also curious to note, with the Myc tagged Med15 ${ }^{\mathrm{S} 288 \mathrm{C}}$ is predicted to be $140 \mathrm{kDa}$ with $\mathrm{pl}$ at 6.61 and Med15 ${ }^{\mathrm{YJM} 789}$ is predicted to be 142

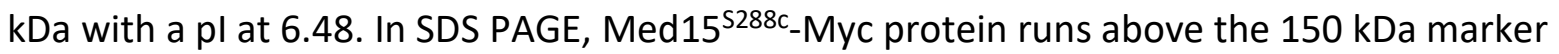

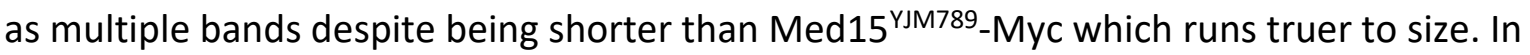
part, the differences in Med15 protein levels could be attributed to differences in mRNA levels. Global mRNA levels were quantified by Illumina sequencing of three biological

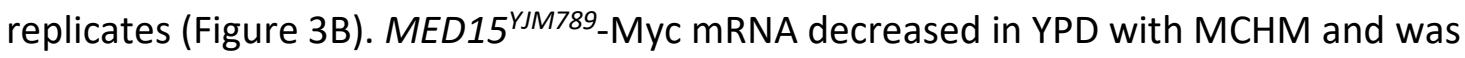
equivalent in YM irrespective of MCHM. The levels of MED15 ${ }^{5288 c}$-Myc mRNA levels also tracked with protein levels. The MED15 promoter contains 4 SNPs that were included on the plasmid which are in relation to the start codon of S288c to YJM789: A-8T, A-209G, A-365G, and T-449C. Next, the stability of the Med15 proteins was measured by treatment with

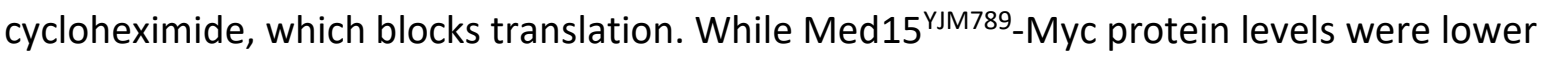
than Med15 ${ }^{\text {S288c }}-$ Myc by the end of the time course, Med15 $5^{\mathrm{YJM} 789}$ had decreased more relative to the levels of Med15 $5^{\text {s288c }}$ (Figure 3C). 


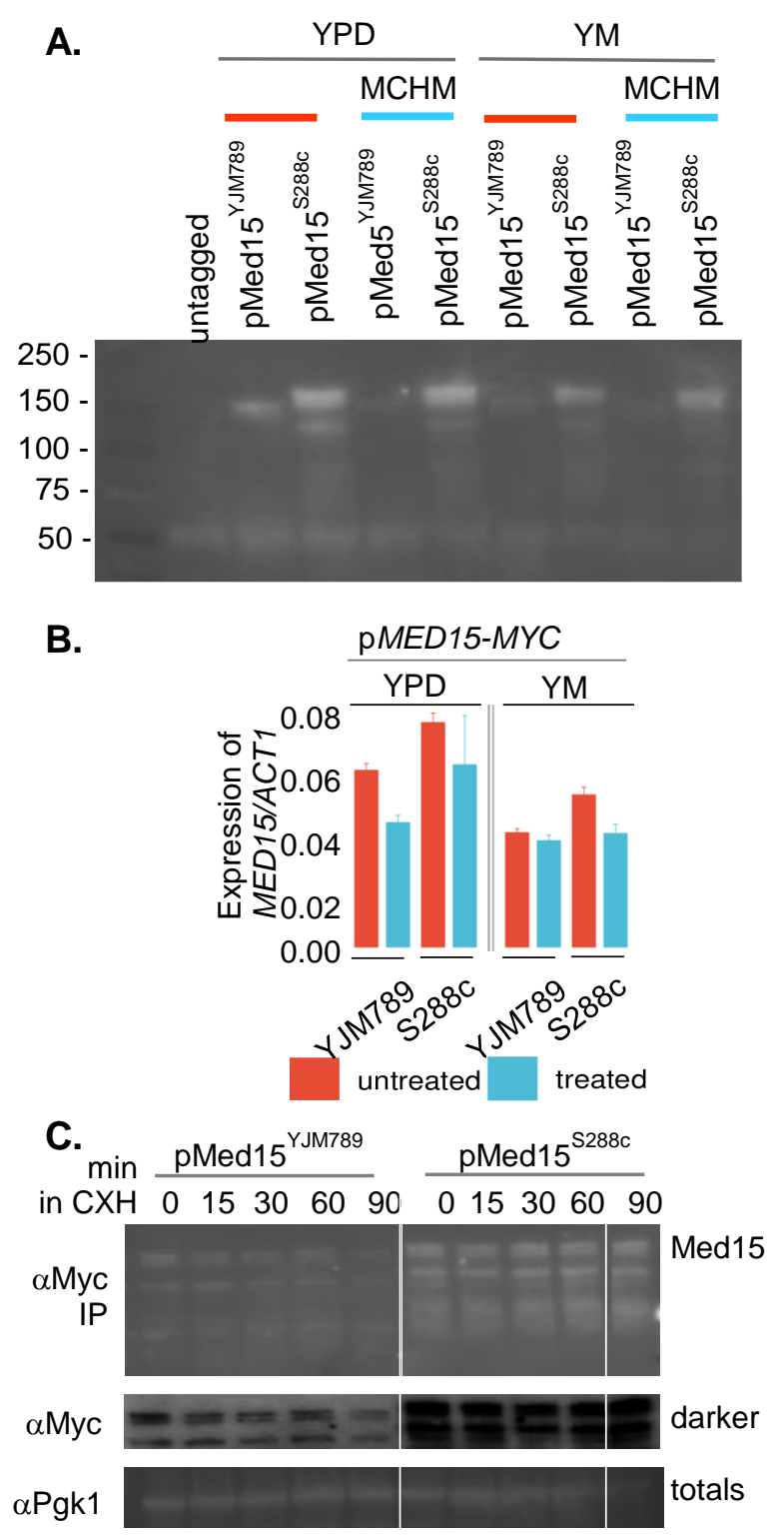

Figure 3 Changes in the expression levels of different alleles of Med15 treated with MCHM. (A) Protein levels of Med15-13xMyc expressed from a plasmid in BY4741 med15 yeast. Yeast were grown in selective media until mid-log and then shifted to $550 \mathrm{ppm}$ MCHM for 90 minutes. Med15-13xMyc was immunoprecipitated from equal amounts of protein extract. (B) mRNA levels of MED15 expressed from a plasmid in BY4741 med15 yeast normalized to ACT1 mRNA. Transcript levels were extracted from RNAseq data. Yeast were grown in YPD (with G418) or YM (yeast minimal media supplemented with HLM) and then treated with 550 ppm MCHM for 30 minutes. (C) Western blot of Med15-Myc immunoprecipitated from BY4741 carrying YJM789 and S288c alleles of Med15 from yeast grown in YPD at 0, 15, 30, and 90 minutes after the addition of cycloheximide. The total lysate was run separately and 
Pgk1 was blotted as a loading control. (Contributed by Jen Gallagher: A and C) (Contributed by Amaury Pupo: B).

Med15 is important for response to many different stresses, and to determine which genes were differentially regulated RNAseq was carried out. BY4741 and its isogenic med15 knockout were grown to log-phase and then treated with MCHM. In YPD, 149 genes were upregulated, and 184 genes were downregulated in the med15 knockout compared to BY4741 (Figure 4A and Table S1). The downregulated genes were related to metabolic processes of nucleosides and ribonucleosides, pyruvate metabolism, carbohydrates, and organophosphates catabolism, small molecule biosynthesis, oxidoreduction coenzyme metabolism, among others (Figure S3). In part downregulation of these metabolic genes in absence of the Med15 protein may explain the reduced growth of the knockouts in rich media or regulation of these genes were dependent on Med15, then downregulation would slow the growth. Other conditions that reduce growth such as petite yeast (Pupo et al., 2019b) or treatment with chemicals that reduce growth (Rong-Mullins et al., 2018), demonstrate downregulation of similar pathways. In YPD, 46 GO terms were upregulated and 76 were downregulated, while in YM, 35 were upregulated and 72 were downregulated. This set was not enriched in genes related to heat-shock response, drug/ toxin transport, stress response, and cellular import as in Ansari et al. (2011) or in ribosome biogenesis as in Miller et al. (2012). Sporulation related genes were upregulated (Figure S4), as previously reported (Ansari et al., 2011; Larsson et al., 2013); although, they are not yet known to have functional relevance in haploid cells. There were also genes involved in cell development, reproduction, morphogenesis and sulfur compound biosynthetic process. 
Previously a study found that genes were upregulated for sulfur metabolism in a med15 mutant (Ansari et al., 2011).

When MCHM was added, the number of differentially expressed genes increased in the med15 mutants. There were 468 genes upregulated and 278 downregulated (Figure $4 \mathrm{~B}$ and Table S1). There was extensive overlap in metabolic pathways in the downregulated genes in the med15 knockout compared to BY4741 in YPD only and YPD + MCHM, with only three more GO terms appearing: monosaccharide metabolism and organic acid and carboxylic acid biosynthesis (Figure S3). The difference was significant in the upregulated genes, not only in the number but in their functionality, as the GO terms overlap was low and a wide set of new terms related to ribosomes, polyamine transport and RNA export from the nucleus appears. It is of note that in our study, med15 deletion caused the upregulation of ribosome biogenesis genes, contrary to the downregulation observed in Miller et al. (2012b). Also, their observed downregulation of this set of genes was the same in wildtype versus med15 under osmotic stress, while we only observed the upregulation in the presence of $\mathrm{MCHM}$, suggesting a fundamentally different mechanism of responding to osmotic stress and MCHM induced stress in yeast.

By directly comparing the Med15 $5^{\mathrm{YJM} 789}-\mathrm{Myc}$ and Med15 $5^{\mathrm{S} 288 \mathrm{C}}-\mathrm{Myc}$ effect on gene expression, Med15 ${ }^{\text {YJM789 }}$-Myc changed the expression of 69 genes and Med15 $2288 \mathrm{C}-$ Myc 23 genes compared to BY4741 when treated with MCHM in YPD (Figure $4 \mathrm{C}$ and D, respectively, Table S1). The functional impact may be minimal as no term came out of the $\mathrm{GO}$ analysis (Figure S3 and S4). Eight out of the nine downregulated genes in Med15 ${ }^{\mathrm{YJM} 789}-\mathrm{Myc}$ vs BY4741 were involved in small molecule biosynthetic process (Figure S2). Besides ribosome biogenesis, 
there were upregulated genes related to rRNA processing, ribonucleoside and glycosyl

compound biosynthetic processes and ion transport (Figure S4).

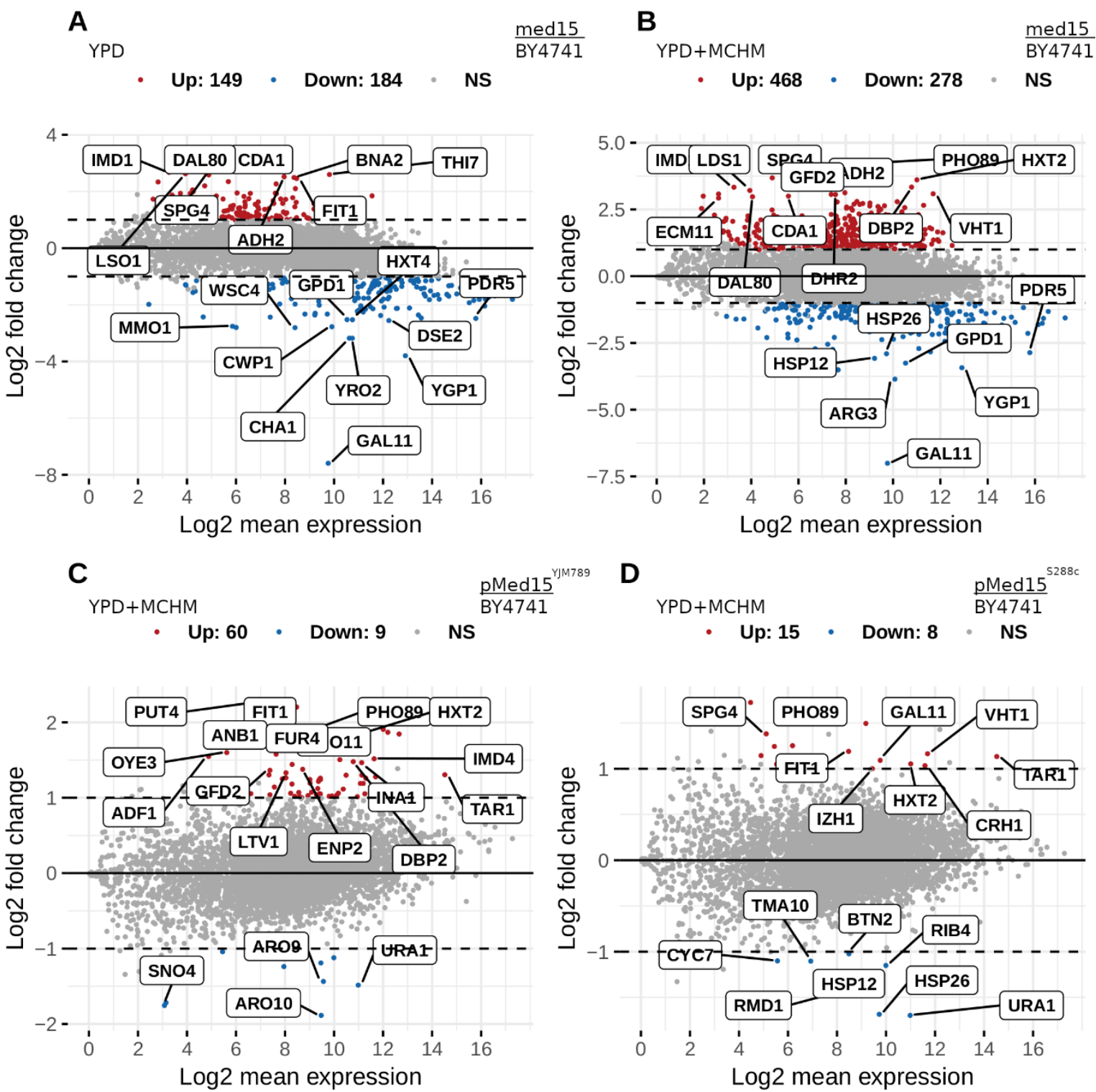

Figure 4 Changes in the transcriptome of BY4741 yeast carrying different alleles of Med15 treated with MCHM grown in YPD. (A) Differentially expressed mRNA from wildtype yeast (BY4741) compared to a med15 knockout strain grown in YPD. (B) Differentially expressed mRNA from wildtype yeast (BY4741) compared to a med15 knockout strain grown in YPD then shifted to 400 ppm MCHM for 30 minutes displayed on a log scale. (C) Differentially expressed mRNA from wildtype yeast (BY4741) compared to a med15 knockout strain carrying Med15 ${ }^{\mathrm{YJM} 789}$ expressed from a plasmid grown in YPD then shifted to $550 \mathrm{ppm}$ MCHM for 30 minutes. (D) Differentially expressed mRNA from wildtype yeast (BY4741) compared to a med15 knockout strain carrying Med15 ${ }^{\mathrm{S} 288 \mathrm{C}}$ expressed from a plasmid grown 
in YPD with G418 then shifted to 550 ppm MCHM for 30 minutes. (Contributed by Amaury Pupo).

The change of the media (YM instead of YPD) provoked a significant change in gene expression variation among the different cases being compared (Figure S5 and Table S1). But the functional analysis of downregulated genes was strikingly similar to that of yeast grown in YPD (Figure S4 and S7). The functional analysis of upregulated genes in YM showed a different picture, with med15 knockout versus BY4741. GO terms were almost the same regardless of the presence of MCHM, but three new GO terms appeared in Med15 ${ }^{\mathrm{YJM} 789}$ _ Myc versus BY4741: sulfate assimilation, cysteine biosynthesis, and secondary metabolism.

The Mediator tail module preferentially associates with SAGA-dominated genes (Huisinga and Pugh, 2004). We determined if the differentially expressed genes from this RNAseq overlaps with the SAGA and TFIID-dominated categories. From the supplementary table where all genes are labelled depending on their SAGA/TFIID dominated status, analyzed the appropriated annotation for the 1111 unique genes that were differentially expressed in any of the comparisons (Table S1). From these, 1012 genes were found in the supplementary table (Huisinga and Pugh, 2004). We have added a pie chart with the labelling of our relevant genes (Supplemental Figure S8). As can be seen, the SAGA-dominated set is a minority of a $26 \%$, but given that SAGA-dominated gene are just $10 \%$ of the genome (Huisinga and Pugh, 2004), then there was an enrichment of those genes (of 2.6X compared to a randomly sampled set of genes of equivalent size).Med15 binds upstream of many genes (Jeronimo and Robert, 2014). Three genes were chosen for further characterization, PTR2, PUT4, and YDJ1 (Dunn, Gallagher, and Snyder, unpublished). Ptr2 is a dipeptide transporter (Island et al., 1991) and Put4 is the high-affinity proline permease (Vandenbol et 
al., 1989). Nitrogen catabolite repression downregulates transporters and permeases of nonpreferred nitrogen sources when preferred nitrogen sources such as ammonium or glutamine (MSG) are available (reviewed in Mara et al., 2018). At the cell membrane, both of these proteins are downregulated via endocytosis when shifted to a preferred carbon source, with Put4 degradation being faster than Ptr2 (Villers et al., 2017). Except in MCHM treatment in YM, the levels of PTR2 were significantly decreased and the levels of PUT4 significantly increased in Med15 $5^{\mathrm{YJM} 789}$ with respect to Med15 $1528 \mathrm{C}$ in all other conditions, while the levels of YDJ1 expression remained the same (Figure 5A). The knockouts of these genes conferred MCHM sensitivity in YPD. However, in YM, only the ydj1 yeast strain was also sensitive to MCHM (Figure 5B). The role of Ydj1, a protein chaperone, on Med15 function was further characterized. MCHM acts as a hydrotrope that alters protein solubility which is related to protein conformation. Swapping the Med15 alleles in the ydj1 knockout had no effect on growth. The ydj1 knockouts were slow-growing in BY4741 (Figure 5B and C) and ydj1]is lethal in W303 ((Caplan and Douglas, 1991). The impact of the loss of Ydj1 on Med15 protein levels was measured by western blot (Figure 5D). The Myc tagged protein isoforms were more heterogeneous in size in the $y d j 1$ mutant and the levels of Med15 $15^{\text {YJM789 }}$ increased to match that of Med15 ${ }^{\mathrm{S} 288 \mathrm{c}}$. The slowest migrating band of Med15 $5^{\mathrm{YJM} 789}$ increased to match that of Med15 ${ }^{\text {s288c }}$.

Med15 contains multiple phosphorylations with the C-terminal MAD. It is unknown if these phosphorylations are regulated in a stress-dependent manner. Both alleles of Med15-Myc run as multiple bands that did not appear to change in MCHM treatment (Figure 3A). To determine if other stressors could alter the isoforms of Med15, expressing Med15 ${ }^{\mathrm{S} 288 \mathrm{C}}$-Myc were treated with either MCHM or hydrogen peroxide over a 90-minute time course. There 
was no visible change in the pattern of Myc-tagged proteins in the western blot (Figure S9A). While the effects of MCHM on yeast clearly point to an increase in ROS stress for the cell, wildtype cells seem to be robust enough, on average, to limit this stress, while mutants in certain pathways cannot. To test this hypothesis, we also performed the DHE assay on med15 mutants (Figure S9B). The endogenous levels of ROS were higher in med15 and when treated with hydrogen peroxide increased ROS compared to BY4741. The wildtype and mutant strains showed a similar pattern of DHE fluorescence when treated with MCHM, with the appearance of a high ROS population peak that was less intense and broader than hydrogen peroxide. The major difference from the wildtype was an increase in the size of the high ROS population peak. Therefore, med15 mutants may have an innate sensitivity to MCHM due to their inability to maintain ROS homeostasis.

A.

\section{B.}
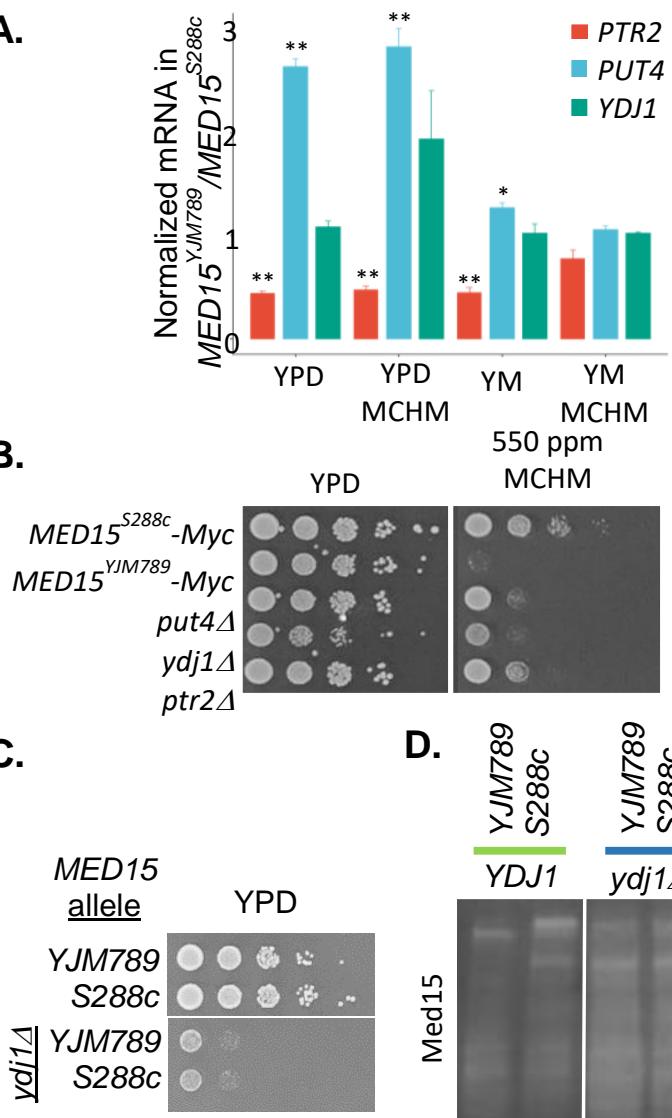

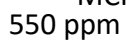
MCHM

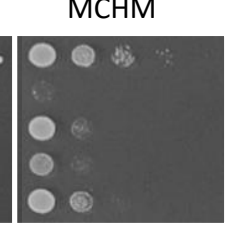

D. $\begin{aligned} & \infty \\ & \infty \\ & \substack{\infty \\ j} \\ & \substack{\infty \\ \infty}\end{aligned}$

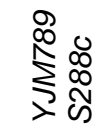

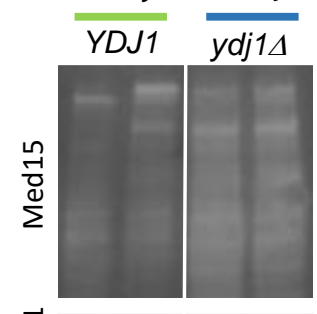

Figure 5 Conditions that affect the stability of Med15. (A) Expression levels of PTR2, PUT4, and YDJ1 extracted from RNAseq data from supplemental table ST1 (B) Plasmids containing Med15 ${ }^{\text {YJM789-Myc and }}$ Med15 ${ }^{\text {S288c }}$-Myc were transformed into single mutants of med15. The put4, ptr2, and ydj1 in the BY4741 background were grown and serial dilutions of yeast on YPD were grown for 2 days at $30^{\circ} \mathrm{C}$ and then photographed. (C) Serial dilution of yeast knockouts of ydj1 yeast expressing YJM789 or S288c alleles of Med15-Myc on YPD. (D) Western blot of YJM789 or S288c alleles of Med15-Myc immunoprecipitated from BY4741 or the ydj1 mutant which were grown in YPD. (Contributed by Amaury Pupo: A) (Contributed by Jen Gallagher: B,C and D). 
The growth analysis, protein levels, and transcriptomics of the Med15 allele swaps were carried out with Myc tagged alleles (Figures 2-5). Numerous studies have used these epitope tags and on occasion have noticed negative effects on the function of the protein. The typical control is testing the growth of yeast. Strains carrying either of the Myc tagged alleles experienced growth indistinguishable from untagged alleles on YPD and YM in BY4741 and YJM789 (Figure 2B). However, we began to question this pattern, at least in some stress conditions, upon deeper analysis of the RNAseq (Figure 4D and S4D). Med15 was among the overexpressed genes in Med15 ${ }^{\text {s288c }}$-Myc vs BY4741 (log2FC 1.1) in MCHM treatment and 22 other genes also changed expression (Figure 4D). There was no statistical difference in expression levels of the tagged allele in untreated YPD or YM (Figure S10A and B). Yeast expressing Med15 ${ }^{\text {s288c }}$-Myc showed a few genes upregulated in both YPD and YM, such as PUT4 and PHO89. Genes that were downregulated encode protein chaperones: HSP30, HSP4, and SSA4 (Figure S10A and B). Initial experiments were carried out in the prototrophic S288c (GSY147) to compare to YJM789 (Figure S1A) and the Med15 ${ }^{\text {S288c }-M y c}$ cloned was from genomically tagged GSY147 and YJM789 and inserted into pRS316. However, to take advantage of the Yeast Knockout Collection and study allele effects in a single genetic background, subsequent experiments, including RNAseq, were carried out in BY4741. Med15 polyQII from GSY147 contains 23 glutamines, while BY4741 has 18 glutamines (Figure 1E). We can compare the impact of shorter polyQ tracts in Med15 by comparing RNAseq from yeast carrying pMED15 ${ }^{\text {S288c }}$-Myc to BY4741. Genes such as PHO89, PUT4, SSA4, HSP30, URA1, and MDH2 were differentially expressed in both YPD and YM (Figure S10A and B). All strains tolerated MCHM better in YM compared to YPD (Pupo et al., 2019b) and intracellular levels of metals and other ions increase in MCHM, including 
phosphate which doubles in YPD with MCHM treatment (Pupo et al., 2019b). Knockouts of pho89 and a related phosphate transporter, pho84 were grown in the presence of MCHM. Despite $\mathrm{PHO} 89$ expression increasing as measured in RNAseq, the knockout grew the same as BY4741 and the pho84 mutant was sensitive to MCHM in YPD and YM (Figure S10C). PHO89 expression was higher in med15 knockouts in all conditions tested (Figure 4A, 4B, S4A and S4B), and we conclude that Med15 negatively regulates expression of $\mathrm{PHO} 89$ independent of MCHM. In the RNAseq, the presence of the Myc tag was not taken into account.

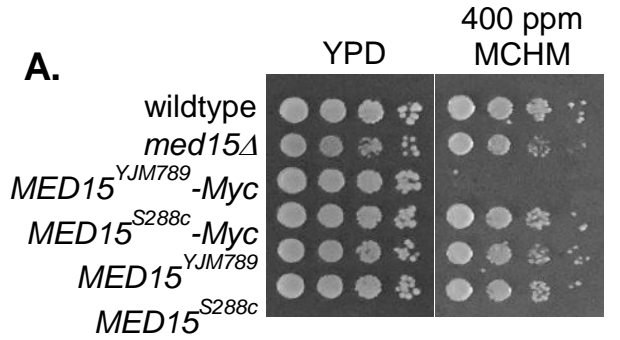

C.

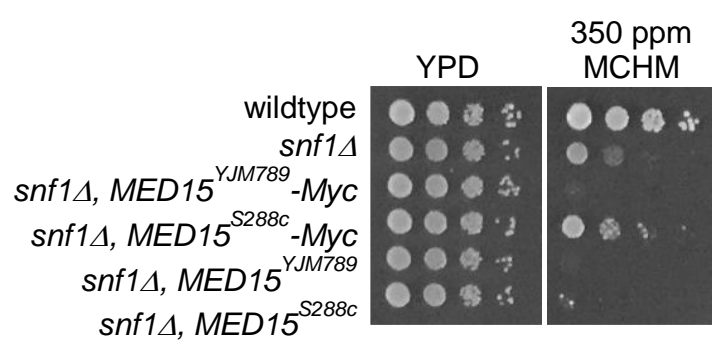

B. Bildtype
med15
snf1
reg1 1
54, snf1
54 , reg1

D.

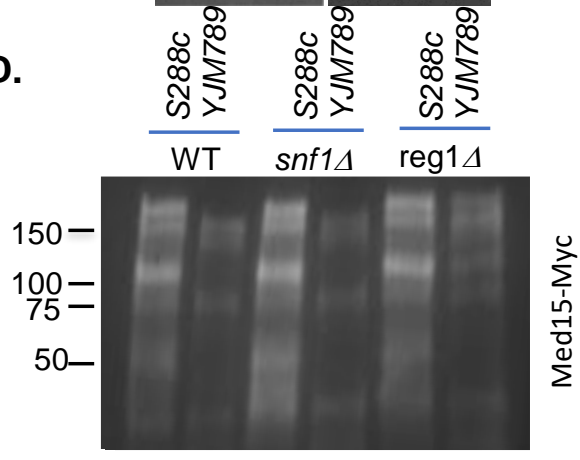

Figure 6 Impact of Snf1 and Reg1 on yeast expressing different Med15 alleles. (A) Serial dilutions of BY4741 with different alleles of Med15 that are untagged or C-terminally tagged with 13xMyc grown on YPD or 400 ppm of MCHM and photographed after three days of growth. (B) Serial dilution of BY4741 with single and double mutants containing med15, snf1, and reg1 knockouts grown on YPD or $350 \mathrm{ppm}$ of MCHM. Plates were photographed after two days of growth. (C) Serial dilutions of BY4741 snf1 1 mutants expressing different alleles of Med15 with and without the 13xMyc tag grown on YPD or 350 ppm of MCHM. Plates were photographed after three days of growth. (D) Western blot of YJM789 or S288c alleles of Med15-Myc immunoprecipitated from BY4741 grown in YPD with SNF1 or REG1 deleted. 
Between Med15 ${ }^{\mathrm{S288C}}$ and Med15 ${ }^{\mathrm{BY}}$, only polyQII differed (18 versus 23Q). To explore whether the variation in the polyQIl or the presence of the Myc tag was affecting MCHM response, Med15 was tagged at its genomic location in BY4741 and compared to BY4741 carrying Med15 $5^{\mathrm{S288c}}$ with and without the Myc tag. Yeast with Med15 ${ }^{\mathrm{S288c}}$ without the Myc tag grew slower than yeast carrying Med15 $2288 \mathrm{c}-$ Myc. The presence of the Myc tag on Med15 ${ }^{\mathrm{BY}}$ slightly increased the MCHM tolerance relative to $\mathrm{Med} 15^{\mathrm{BV}}$ but not as much as yeast with Med15 $288 \mathrm{c}$-Myc (Figure S10D). However, these differences were only seen at a lower concentration of $350 \mathrm{ppm} \mathrm{MCHM}$ at day 2 compared to concentrations used for RNAseq or initial screening for three days of growth (Figure 6A). The effect of the Myc tag on Med15 was directly tested by cloning endogenous Med15 ${ }^{\mathrm{YJM} 789}$ without the Myc tag and testing growth of yeast on MCHM. The difference in MCHM sensitivity was lost when the Myc tag was absent (Figure 6A). In a genomic screen of the knockout collection for MCHM sensitive mutants, both snf1 and reg1 mutants were identified (Ayers et al., 2020). Myc is likely phosphorylated by Snf1 in vitro (Martin Schmidt, personal communication). Reg1 is the regulator subunit the phosphatase that dephosphorylates Snf1 at T210 which downregulates its kinase activity. In a reg1 mutant, the SNF1 complex has more kinase activity (reviewed in Hedbacker and Carlson, 2008). snf1 mutants grow slightly slower than wildtype on YPD and are more sensitive than the med15 mutant to MCHM while reg1 mutants grew only a little slower (Figure 6B). The snf1, med15 double mutant growth was between the two single mutants and the reg1, med15 double mutant was closer to the med15 single mutant. In snf1 mutants, the allele of Med15 expressed had no impact on

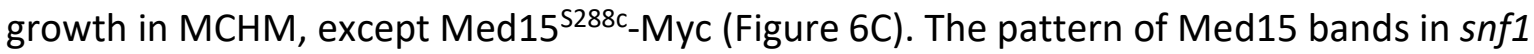
and reg1 mutants was measured on a western blot. Both Med15 alleles were similar in the 
wildtype and snf1 mutant, but Med15 ${ }^{\mathrm{YJM} 789}-\mathrm{Myc}$ shifted up and became more similar to Med15 ${ }^{\text {S288c }}$-Myc in the reg1 mutant (Figure 6D).

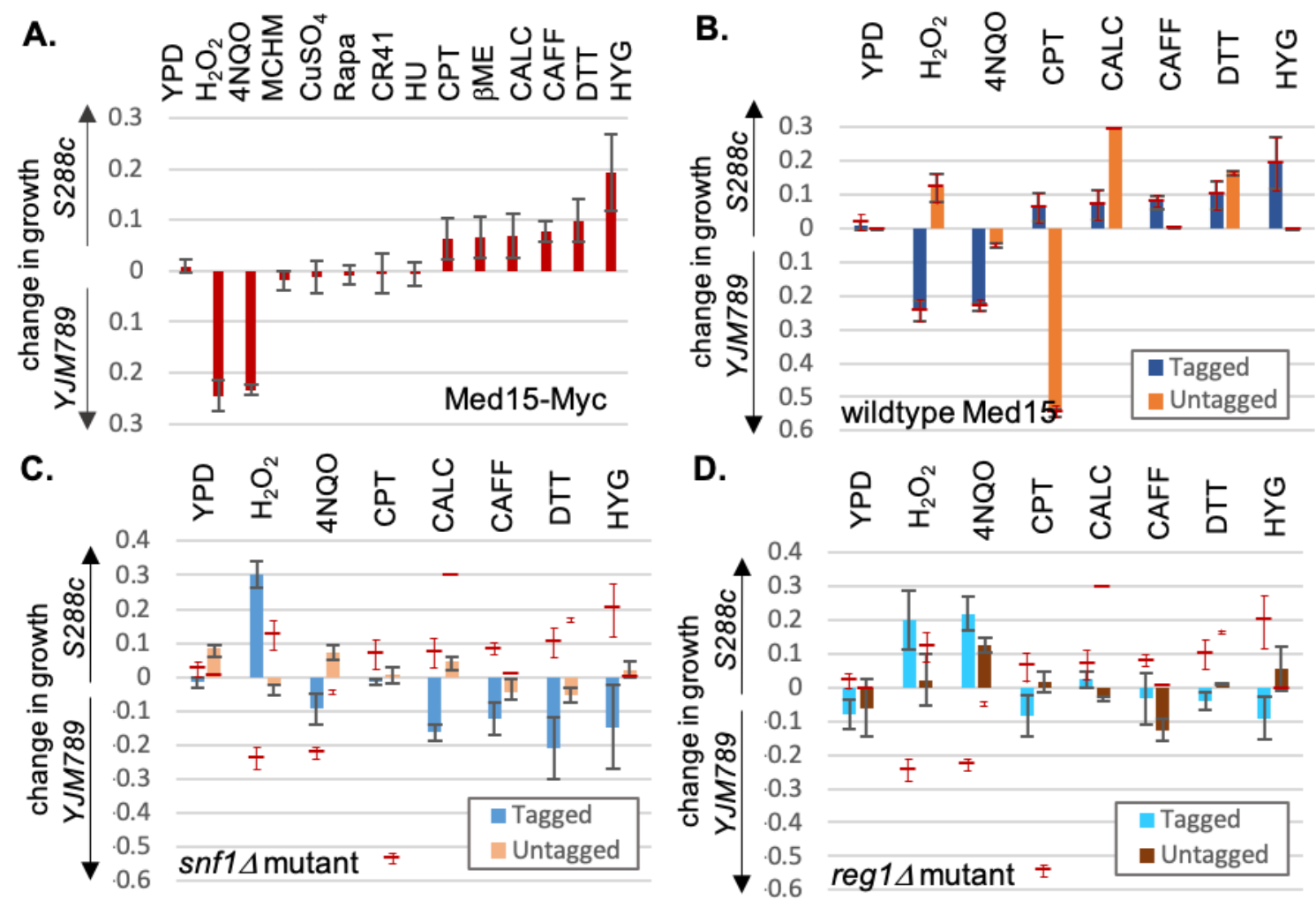

Figure 7 Quantitative growth assays of BY4741 med15 carrying different alleles of Med15 in snf1 and reg1 mutants with different drugs. At the time when there was the maximum growth difference, the $\mathrm{OD}_{600}$ of yeast carrying Med15 ${ }^{\mathrm{S288c}}$ was subtracted from $\mathrm{OD}_{600}$ of yeast carrying Med15 ${ }^{\mathrm{YJM}} 789$. Values above the $y$-axis indicate increased growth yeast with the Med15 $5^{\text {S882C }}$ and values below the $y$-axis indicate that yeast with Med15 ${ }^{\mathrm{YJM} 789}$ grew better than yeast with the other allele. The following chemicals were added: hydrogen peroxide $\left(\mathrm{H}_{2} \mathrm{O}_{2}\right)$, 4-Nitroquinoline 1-oxide (4NQO), 4-Methylcyclohexanol (MCHM), copper sulfate $\left(\mathrm{CuSO}_{4}\right)$, rapamycin (Rapa), glyphosate (CR41), hydroxyurea (HU), beta-mercaptoethanol ( $\beta$ $M E$ ), calcofluor white (CALC), caffeine (CAFF), dithiothreitol (DTT), and hygromycin (HYG). (A) Growth of BY4741 med15 yeast carrying different alleles of Med15-Myc. (B) Growth of BY4741 med15 yeast carrying different alleles of Med15 (untagged, blue) or Med15-Myc (tagged, orange). (C) Growth of BY4741 med15 and snf1 yeast carrying different alleles of Med15 (untagged, light blue) or Med15-13xMyc (tagged, light orange). The respective values of wildtype yeast from panel $B$ are shown as a thin red line with the standard deviation range is shown as thin red lines. (D) Growth of BY4741 med15 and reg1 yeast carrying different alleles of Med15 (untagged, cyan) or Med15-Myc (tagged, brown). The respective values of wildtype yeast from panel $B$ are shown as a thin red line with the standard deviation range is shown as thin red lines. (Contributed by Jen Gallagher: A). 
The two alleles of Med15-Myc conferred different phenotypes not only against MHCM but also other chemicals (Figure 7A). Yeast were grown in an automatic plate reader and the growth difference maximum between alleles during log-phase was plotted. Yeast with

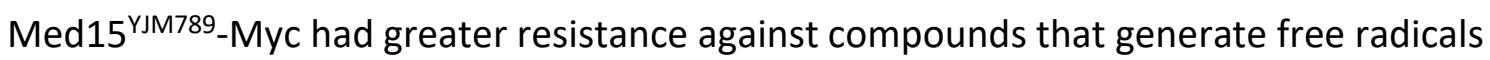
directly, such as hydrogen peroxide and $4 \mathrm{NQO}$, which generates free radicals as it is metabolized (Rong-Mullins et al., 2018). MCHM is a volatile compound (Gallagher et al., 2015b), and when quantitative growth assays were carried out in small volumes, the MCHM evaporates before the end of the growth assay, so growth was only marginally slower in yeast with Med15 ${ }^{\text {YJM789-Myc. The Med15 }}{ }^{\text {S288c }}-$ Myc allele conferred resistance to reducing agents that cause unfolded protein response such as beta-mercaptoethanol and DTT, and to DNA damaging chemicals such as camptothecin, and to hygromycin which inhibits translation. Yeast with Med15 ${ }^{\mathrm{S} 288 \mathrm{c}}$-Myc were also more resistant to caffeine, which in part can mimic the effects of TOR inactivation, but not to rapamycin which also inhibits TOR. Other chemicals that did not differentially inhibit yeast with different Med15 alleles were Credit41 (glyphosate-based herbicide) which inhibits aromatic amino acid biosynthesis and hydroxyurea which arrests cells in S phase by depleting nucleotides. From this panel of 13 chemicals, 7 were chosen for further characterization in yeast with different alleles of Med15 with and without the Myc tag (Figure 7B). The Myc tag at times flipped the preference of the allele and at other times exaggerated the differences. Only in the presence of caffeine and hygromycin was no difference in growth seen between the untagged alleles, yet increased growth seen of the yeast carrying the Med15 ${ }^{\text {S288c }}$-Myc allele. In calcofluor white, the Med15 $5^{\text {s288c }}$-Myc yeast grew better and in camptothecin, yeast with Med15 ${ }^{\mathrm{s} 288 \mathrm{c}}$-Myc grew better while the untagged Med15 ${ }^{\mathrm{s} 288 \mathrm{c}}$ was marginally better than Med15 ${ }^{\text {YJM789 }}$ for both chemicals. 
To assess the impact of the loss of Snf1 and Reg1, quantitative growth assays were conducted in allele swaps with snf1 and reg1 mutants. snf1 mutants with untagged Med15 $5^{\text {S288c }}$ had slightly improved growth compared to snf1 Med15 ${ }^{\mathrm{YJM} 789}$ in many conditions including in YPD but was not as much as wildtype yeast with the same allele (Figure 7C). In

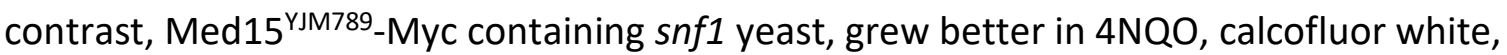
caffeine, DTT, and hygromycin. Hydrogen peroxide and 4NQO both produce ROS but by different mechanisms. Hydrogen peroxide is directly converted to ROS and $4 \mathrm{NQO}$ is converted through a respiration-dependent mechanism (Rong-Mullins et al., 2018). snf1 yeast with Med15 ${ }^{\text {s288c }}$-Myc allele grew better in hydrogen peroxide than wild type yeast with Med15 ${ }^{\text {s288c }}$-Myc. Loss of Reg1 caused a similar trend in the changes of growth with the notable exception of 4 NQO. In that case, the reg1 Med15 $5288 \mathrm{c}-$ Myc grew better than wildtype (Figure 7D).

\section{Discussion}

Expansion of polyQ in proteins was discovered to be the cause of numerous neurodegenerative diseases. Slippage of the DNA polymerase during DNA replication and unequal homologous recombination causes expansion and contraction of the repeats. In Huntington's disease, expansions over 30 repeats are considered pathogenic and induce aggregation of Huntington protein. In vivo, these aggregates form foci in the cell that under static imaging cannot be distinguished from liquid phase-separated condensates. The function of hydrotropes in biology is recently coming into appreciation and regulates the reversible formation of protein condensates. Several proteins in the Mediator complex have IDRs that promote liquid phase-separated condensates with TFs (Boija et al., 2018). Intrinsically disordered regions such a polyQ tracts facilitate phase separation (Boija et al., 
2018; Brzovic et al., 2011b; Hyman et al., 2014; Jedidi et al., 2010; Tuttle et al., 2018;

Warfield et al., 2014). The two polyQ tracts in Med15 vary between 12 and 27 repeats.

Changes in polyQ tracts of Med15 changed the response to numerous chemicals and were dependent on Snf1. Throughout the tail proteins of the Meditator, there is genetic variation that has yet to be explored. Reciprocal hemizygosity of med15 mutants did not differentiate between the YJM789 or BY4741 alleles. Both hemizygous mutants were more sensitive to MCHM than the homozygous mutant, despite the YJM789 strain having a higher tolerance to MCHM than BY4741. This was the case when Med15 was Myc tagged. Allele swapping of

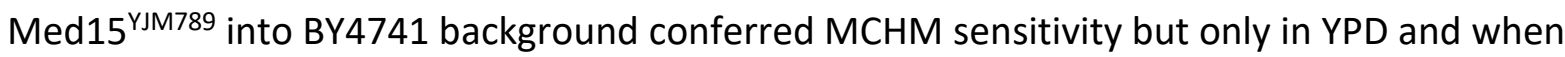
the Myc tag was present. While in YJM789, the expression of Med15 ${ }^{\text {S288c }-M y c ~ d i d ~ n o t ~}$ change MCHM resistance. In both BY4741 and YJM789 strains, the med15 mutants were slow-growing in untreated media, which was not affected at higher concentrations of MCHM, making it appear that at the highest concentrations of MCHM, the YJM789 med15 mutants were resistant to MCHM. MCHM sensitivity induced by expression of Med15 $15^{\mathrm{YJM} 789}$ in BY4741 was not dominant. Therefore, we concluded that the YJM789 Mediator complex can better tolerate Med15 with shorter polyQ tracts, while the BY4741 Mediator is more sensitive to perturbations. Myc possibly increases recruitment of Snf1 to the Mediator when Med15 contains expanded polyQ tracts. MED15 ${ }^{\mathrm{YJM} 789}$ was expressed at slightly lower levels and the protein level was even lower level than Med15 $5^{\mathrm{s} 288 \mathrm{c}}$ and was also less stable. While changes in mRNA levels contribute to lower protein levels, the longer polyQ tracts in Med15 ${ }^{\text {YJM789 }}$ may also slow translation or increase ubiquitin-dependent degradation, as the protein is less stable when the translation was inhibited. 
Ydj1 was required for stability of Med15 protein and it was difficult to assess the role of Ydj1 on Med15 protein stability because of the extremely slow growth of the $y d j 1$ mutants. Ydj1 also has a role at $\mathrm{H} 3$ histone eviction when transcription is induced. Gcn4 binding to promoters was not reduced in a yjd1 mutant (Qiu et al., 2016) or at the GAL1 promoter (Summers et al., 2009). Hsp70 associates with several Hsp40-like proteins including Ydj1, a type $1 \mathrm{Hsp} 40$ that stimulates Hsp70 activity. Ydj1 is localized to the perinuclear and nuclear membranes (Caplan and Douglas, 1991). The role in nucleosome eviction may be indirect by helping to fold Med15. Ydj1 inhibits the SDS-resistant aggregation of the polyQ containing a fragment of $\mathrm{Htt}$ in yeast (Krobitsch and Lindquist, 1999; Muchowski et al., 2000). The Med15 fragment containing the polyQ aggregates in vivo (Zhu et al., 2015) as well as when fulllength Med15 is overexpressed. Ydj1 was required for both alleles of Med15 protein stability as the isomers that were Myc tagged became less distinct maintaining Med15 $5^{\text {YJM789 }}$ true to size compared to Med15 $5^{\text {S288c }}$. Zinc can aid in catalysis as an enzyme cofactor but also stabilize the structure of proteins when bound and Ydj1 binds zinc. In response to zinc starvation, yeast ration their zinc, known as zinc sparing (Wang et al., 2018). Intracellular zinc levels are three times higher when treated with $\mathrm{MCHM}$, and supplementation with zinc improves growth up to a point when too much zinc can no longer rescue MCHM induced growth arrest (Pupo et al., 2019b). Ydj1 protein level is dependent on zinc levels, although transcription was not affected (Wang et al., 2018). For Ydj1, zinc may serve to stabilize the protein structure, protecting it from degradation as it unfolds without zinc. Yjd1 may function to regulate the phase state of Med15 or other components of the Mediator.

Yeast exposed to MCHM upregulate many pathways involved in biosynthesis; however, these yeasts do not appear to be lacking for these nutrients. Amino acids, inositol, zinc, and 
phosphate levels are increased (Pupo et al., 2019c, 2019b). Since the 2014 MCHM spill, several studies have measured the toxicological effects of MCHM on diverse species but have not addressed the mechanism of toxicity during acute exposure (Cozzarelli et al., 2017; Eastman, 2014; Gwinn et al., 2018; Han et al., 2017; Horzmann et al., 2017b; Paustenbach et al., 2015b; Phetxumphou et al., 2016; Weidhaas et al., 2016). One possible explanation of MCHM's diverse effects is as a stable hydrotrope MCHM changes the structure of nutrient sensors so they no longer sense extracellular compounds. In YM, more genes were differentially expressed and yet yeast were more tolerant to MCHM. Compared to YPD, in YM, nutrient transporters are downregulated, and the biosynthetic pathways are upregulated which could mitigate the effect of MCHM. Familiar compounds such as ATP and RNA are hydrotropes and induce protein condensates which are separated from the surrounding proteins in liquid phase separation. This serves to concentrate functional proteins reversibly rather than inactivate them as protein aggregates. MCHM is a cyclic hydrocarbon that is relatively more stable than RNA and ATP in the cell. MCHM was detected in sediment ten months after the spill (Cozzarelli et al., 2017). MCHM is primarily degraded into aldehydes and carboxylic acids (Lan et al., 2015) which generates ROS (Cui et al., 2017). The increased ROS seen in this study was seen at 12 hours after incubation and therefore increase in ROS from degradation would be a secondary effect and the hydrotropic effect of MCHM would be the primary effect on the transcriptome and metabolome, especially at early time points.

Among the differentially expressed pathways in the med15 mutant, PHO89 was noted because Pho89 is a high-affinity transporter that is induced in inorganic phosphate limiting conditions (Martinez and Persson, 1998) and intracellular levels of phosphate increase in 
MCHM exposure (Pupo et al., 2019b). The other high-affinity inorganic phosphate transporter is Pho84, which is also induced in phosphate limiting conditions (Bun-Ya et al., 1991). PHO84 expression was 4-fold downregulated in the med15 mutant grown in YPD but was not significantly different in other strains and conditions. While $\mathrm{PHO} 89$ and $\mathrm{PHO} 84$ are both induced in phosphate limiting conditions, the kinetics are slightly different due to the different transcription factors and kinases that regulate their expression (Serra-Cardona et al., 2014). Pho2/ Pho4 are transcription factors that regulate the $\mathrm{PHO}$ regulon and the expression of secreted acid phosphatases, Pho5, Pho11, and Pho12 was also increased in MCHM treatment. Yet there are other signaling pathways that affect the regulation of PHO89, such as Snf1, which phosphorylates Mig1 and Nrg1 under stress and regulate PHO89 expression but not PHO84 expression (Serra-Cardona et al., 2014). Pho84 and Pho89 have nonredundant roles in MCHM response. Despite $\mathrm{PHO} 89$ being differentially expressed, only the pho84 mutant was MCHM sensitive. It is likely that Med15 directly regulated PHO84 expression because it physically binds the $\mathrm{PHO} 84$ promoter, and it is not found at the PHO89 promoter (B. Dunn, J. Gallagher, and M. Snyder, unpublished).

The multiple bands of Med15 proteins shift between the different alleles. In order to visualize Med15, the 13xMyc tag was integrated at the C-terminal end. While possible that the multiple bands represent $\mathrm{N}$-terminal degradation products, most of these bands migrate slower than the predicted size of full-length Med15-Myc. Several lines of evidence pointed us to investigate whether Snf1 regulates Med15. Snf1 has been copurified with the Mediator complex (Uthe et al., 2017). Med15 has several phosphorylations in the C-terminal MAD. The snf1 mutant is MCHM sensitive (Ayers et al., in preparation) and Snf1 has a role in regulating PHO89 (Serra-Cardona et al., 2014). In the snf1 knockout, the impact of 
changes in the polyQ tract was only seen when Med15 was Myc tagged in MCHM treatment. In calcofluor white, caffeine, DTT, and hygromycin treatments, loss of Snf1 flipped the response of strains carrying untagged alleles of Med15. Med15 ${ }^{\text {S288c }}$ grew better than yeast with Med15 $15^{\mathrm{YJM} 789}$ in these stresses while yeast with Med15 ${ }^{\mathrm{YJM} 789}$ and snf1 were more resistant in hydrogen peroxide. In western blots, the pattern of Med15 bands did not change in snf1 knockout but did in the reg1 knockout. Snf1 can be overactivated by knocking out Reg1, the repressor of SNF1. We did not address the nature of the different bands but they are different from N-terminally tagged HA-Med15 (Herbig et al., 2010), which looked more like the band patterns of Med15 ${ }^{\mathrm{YJM} 789}$ but ran true to size compared to Med15 ${ }^{\mathrm{YJM} 789}$. Other studies have used Med15 $5^{\mathrm{BY}}$-Myc for western blots, but the studies cropped the western blots so the pattern of bands could not be compared. However, Med15-Myc decreased the association of the rest of the Mediator tail subunits (Zhang et al., 2004). This leads to the hypothesis that a Myc tag on any component of the tail weakens the interaction with the rest of the complex (Ansari et al., 2011). However, a decreased association of Med15-Myc with the Mediator complex does not explain all the results

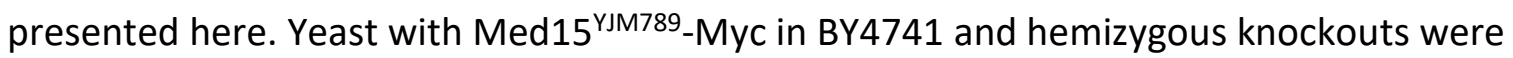
more sensitive than med15 knockouts to MCHM. If the stoichiometry of the Mediator was the only contributing factor to differences, then the phenotypes of the knockouts should show a more extreme version of hypomorphic alleles. This hypothesis was tested by direct comparisons of growth between strains with different Med15 alleles with and without Myc tag and grown in diverse chemicals. The Myc tag can serve as an in vitro target of SNF1 (M. Schmidt, personal communication), and so if SNF1 is already associated with the Mediator, then the Myc tag may increase the SNF1-dependent phosphorylation of the Mediator. 
The differences between Med15 alleles could only be seen in MCHM when Med15 was Myc tagged, while the impact of the tag sometimes exaggerated or lessened differences in other stresses, and sometimes had no impact. The original Myc tag was derived from a peptide from human c-Myc (Evan et al., 1985). Myc is a family of oncogenic transcription factors. Of the multiple peptides tested, only 9E10 did not cross-react with c-myc from other organisms and had low background on western blots (Evan et al., 1985). The 13xMyc epitope tag used here is tandem repeats of EQKLISEEDL (Bähler et al., 1998). Tagging a protein can affect folding, localization, and association with other proteins in a complex. Under normal conditions, Med2, Med3, and Med15 can be recruited to chromatin independent of the rest of the Mediator complex (Anandhakumar et al., 2016; He et al., 2008; Zhang et al., 2004). From the recent structures of the Mediator, Med2 and Med3 bind the C-terminal tail of Med14 in the middle and directly bind Med15. Med15, in turn, binds Med16, and Med5 is at the very distal end of the tail (Figure 1A, (Robinson et al., 2015)). The Med15-Med5-Med16 complex is posited to have a function independent of the full Mediator complex (Larsson et al., 2013). The Myc tag does not include the basic helix turn domain common in transcription factors that binds DNA. Other TFs regulated by the mediator such as Pho4 share homology with the DNA-binding domains of Myc proteins (Shao et al., 1996).

\section{Conclusion}

By their nature, the structure of intrinsically disordered regions are difficult to determine and are important for changes in protein complex conformations (Boehning et al., 2018; Boija et al., 2018; Cho et al., 2018; Patel et al., 2017b; Sabari et al., 2018). The fuzzy/ IDR domains of Med15 and the expansions of the polyQ tracts increased phenotypic diversity. Rim101, a transcription factor with a polyQ tract, affects allele-specific expression in one 
strain background but not others tested (Read et al., 2016). There are multiple phosphorylations in Med15 that regulate the transcriptional response to stress (Miller et al., 2012b). Expression of the longer Med15 allele changed the response to MCHM as other polymorphic transcription factors change the response to other chemical stressors (Gallagher et al., 2014). Variation in key regulators permits the expression of cryptic genetic variation to alter phenotypes. These proteins are master variators.

\section{Materials and Methods}

\section{Strain construction and cloning}

All strains and sources are in Table S2. Med15 sequences were extracted from the resequenced genomes of BY4741, BY4742, AWRI1631, RM11-1a, and YJM789 (Song et al., 2015). Med15 was tagged at the C-terminus with a $13 x$ Myc tag with KanR as the selectable marker in S288c (GSY147), BY4741, and YJM789 as previously described (Bähler et al., 1998; Gallagher et al., 2014). MED15 has a polymorphism just after to the stop codon, so allelespecific primers were used for the 3' Myc tagging and knocking out (Table S3) Primers to the genomic MED15 amplified 499 nucleotides upstream from the start and a 3' tagging primer to include the promoter, coding region, Myc tag, and KanR marker. The PCR product was then cloned into the Notl restriction site in pRS316. MED15 was knocked out in YJM789K5a (isogenic with YJM789 except as a MATa prototroph) and then backcrossed to generate YJM789K6alpha as previously described ((Rong-Mullins et al., 2017). The KanR marker of BY4741 knockout yeast of snf1, reg1, and ydj1 (Giaever et al., 2002) was switched with HygR and then crossed with BY4742 med15::NatR to generate double mutants and then transformed with plasmids containing different alleles of MED15. 
Because of the lack of convenient restriction sites and the repetitive nature, MED15 domain swaps of the alleles proved challenging. Med15 domain swaps were carried out by PCR and then gap repair transformation of plasmid encoding MED $15^{Y J M 789}-M y c$ with polyQ inserts from MED15 ${ }^{\text {S288c }}$. We used inverted PCR to amply $p M E D 15^{Y J M 789}-M y c$ plasmid to linearize the vector with gaps at each of the polyQ repeats. Each polyQ tract from MED15 ${ }^{S 288 c}$ was independently amplified with between 20 and 180 nucleotides of homology with the PCR amplified vector. The vector lacking polyQI and polyQII, respectively from the pMED15 ${ }^{Y J M 789}$ _ Myc plasmid was amplified using primers that generate between 20 and 180 nucleotides overlap at the $5^{\prime}$ and $3^{\prime}$ ends with the insert. and transformed with PCR amplified vector lacking polyQII. Cloning was carried out via gap repair transformation (Gallagher and Baserga, 2004). The inserts were amplified separately with flanking homology to the region around the vector's 5' and 3' ends. The insert and linear vector were transformed into BY4741 med15 yeast and transformants were selected on YPD with G418. based on colony size, as med15 yeast are slow-growing, in combination with selecting for markers on the plasmid. Genomic DNA was extracted and transformed into DH10 beta E. coli and then retransformed into BY4741 med15. All plasmids were verified by Sanger sequencing. Plasmids were rescued by passaging through E. coli and inserts were verified. All primers are listed in Table ST3.

\section{Growth Conditions}

Plasmids were maintained with the addition of $0.5 \mathrm{mg} / \mathrm{ml} \mathrm{G} 418$ in YPD. In minimal media (YM), plasmids were maintained by supplementing media with uracil, histidine, and methionine, or by switching the nitrogen source to glutamate (MSG), and then adding G418 with amino acids as needed. Yeast were grown in liquid media as indicated to mid-log phase 
and then $550 \mathrm{ppm}$ MCHM was added to YPD (650 ppm was added to YM) and cells were harvested after 30 minutes of exposure. Western blots were carried out as previously described ((Gallagher et al., 2014). Solid media plates were cooled to $65^{\circ} \mathrm{C}$ before $\mathrm{MCHM}$ was added and gently mixed until dissolved. Plates were used within 24 hours to limit the evaporation of MCHM. Yeast were serially diluted 10 -fold and spotted on to solid media. Plates were photographed after 2-3 days of growth. For multiple drug screening in the TECAN, the automated plate reader, yeast were grown to stationary phase and then diluted to $0.1 \mathrm{OD}$ with appropriate drugs and read at $O D_{600}$ (Rong-Mullins et al., 2017). The following chemicals were added: $3 \mathrm{mM}$ hydrogen peroxide $\left(\mathrm{H}_{2} \mathrm{O}_{2}\right), 0.25 \mathrm{~g} / \mathrm{ml}$ Nitroquinoline 1-oxide (4NQO), 400 ppm 4-Methylcyclohexanol (MCHM), 1 mM copper sulfate $\left(\mathrm{CuSO}_{4}\right), 7.5 \mathrm{ng} / \mathrm{ml}$ rapamycin (Rapa), 0.1\% glyphosate (CR41), $100 \mathrm{mM}$ hydroxyurea (HU), $20 \mu \mathrm{g} / \mathrm{ml}$ camptothecin (CPT), $8.5 \mathrm{mM}$ beta-mercaptoethanol ( $\beta M \mathrm{ME}), 5 \mathrm{mM}$ calcofluor white (CALC), $2.5 \mathrm{mM}$ caffeine (CAFF), $20 \mathrm{mM}$ Dithiothreitol (DTT), and $50 \mu \mathrm{g} / \mathrm{ml}$ hygromycin. Cells were grown with readings taken every hour. During log-phase, the $\mathrm{OD}_{600}$ of yeast carrying MED15 $15^{S 288 c}$ was subtracted from MED15 ${ }^{Y J M 789}$ at the point of maximal growth difference.

\section{Transcriptomics}

RNAseq was carried out in biological triplicate from yeast grown in YM supplemented with histidine, leucine, and methionine or YPD with G418. PolyA RNA was selected using Karpa Stranded RNAseq library preparation kit according to the manufacturer's instructions (catalog number KK8401). Libraries were sequenced on Illumina PE50bp high output flowcell. Basecalls were performed with Illumina's FASTQ Generation (v1.0.0) available in BaseSpace. Transcripts quantification was done with salmon (v0.9.1) vs the transcripts file 
BY4741_Toronto_2012_cds.fsa (available from

https://downloads.yeastgenome.org/sequence/strains/BY4741/BY4741 Toronto 2012/).

This data are available from GSE, accession number GSE129898

(https://www.ncbi.nlm.nih.gov/geo/query/acc.cgi?acc=GSE129898). Quantification tables were imported to R (3.4.4) and gene-level analysis was created with the tximport (1.6.0) package. For the transcripts to gene translation the homemade $\mathrm{R}$ package TxDb.Scerevisiae.SGD.BY4741 was used. This package was built from the BY4741_Toronto_2012.gff file using GenomicFeatures (1.30.3). The gene differential expression analysis and the data quality assessment were done with DESeq2 (1.18.1). $p$ values were adjusted to an FDR of 0.005. The MA-plots were done with ggpubr (0.1.6). GO term analysis was carried out with clusterProfiler (Yu et al., 2012) (3.6.0). The ORF names from genes up or downregulated in each condition were translated to the correspondent Entrez id using the function bitr and the package org.Sc.sgd.db. The resulting gene clusters were processed with the compareCluster function, in mode enrichGO, using org.Sc.sgd.db as a database, with Biological Process ontology, cutoffs of $p$-value $=0.01$ and $q$ value $=0.05$, adjusted by FDR, to generate the corresponding GO profiles, which were then simplified with the function simplify. The simplified profiles were represented as dotplots, showing up to 15 more relevant categories.

\section{Western blot}

Proteins were extracted, immunoprecipitated, separated in 5-12\% SDS-PAGE, and transferred onto 0.2 micron PVDF as previously described (Gallagher et al., 2014). Antibodies were diluted into freshly made 3\% BSA Fraction V in TBS-Tween. ECL kit and HRP secondary antibodies were used to visualize mouse anti-Myc E910 $(1: 7,500)$ from various 
manufacturers and rabbit anti-PGK $(1: 10,000)$ on a Protein Simple using default chemiluminescence setting.

\section{Flow cytometry}

BY4741 cells were grown to saturation overnight and returned to mid-log phase. Cells were then diluted to a starting $\mathrm{OD}_{600}$ of 0.3 in biological triplicate in YPD media containing MCHM. For measurement of ROS, live cells were pelleted then suspended in 200? phosphate-buffered saline (PBS). The dyed cultures were incubated at $30^{\circ} \mathrm{C}$ for 20 minutes and washed with PBS. A positive control sample of BY4741 cells were treated with $25 \mathrm{mM}$ $\mathrm{H}_{2} \mathrm{O}_{2}$ for 1.5 hours. The DHE dyed samples were then analyzed within 2 hours of harvesting on a BD LSRFortessa using preset propidium iodide detection defaults. Approximately 30,000 events were collected per sample for downstream analysis.

\section{Acknowledgements}

Angela Lee generously gave us the yeast knockout collection. The Gallagher lab provided a fruitful discussion. We would like to acknowledge the WVU Genomics Core Facility, Morgantown, WV for the support provided to help make this publication possible including RNAseq library construction and sequencing. WVU Flow Cytometry \& Single Cell Core Fortessa S10 instrument was supported by OD016165 and WV-INBRE grant 103434 . The Pgk1 antibody was a gift from Jeremy Thorner at the University of California, Berkeley. This work was supported by a grant from the NIH NIES (R15ES026811-01A1).

\section{Conflict of interest}

The authors declare that they have no conflicts of interest with the contents of this article. 


\section{Author contributions}

Conceptualization, JEGG; Investigation, JEGG; Writing - Original Draft Preparation, JEGG;

Writing - Review \& Editing, JEGG, SLS, MCA, and NC; Visualization, JEGG and AP;

Supervision, JEGG; and Funding Acquisition, JEGG.

*SLS -Performed serial dilution assays seen in Figure 6. Performed western blot seen in

Figure 6. Performed quantitative growth assay seen in Figure 7 ( $B, C$ and $D)$.

\section{Supplementary Materials:}

Supplementary materials can be found at: http://www.mdpi.com/1422-0067/21/5/1894/s1

Figure S1 Protein alignment of Med15S288c with human Med15 ortholog. Protein sequences were aligned using ClustalW. Gaps in the alignment are noted with a dash (-). Identical amino acids are noted with an asterisk $(*)$ below the protein sequence. Nonconserved differences are blank. Conserved differences are noted with a colon (:) and a less conserved difference is marked with a period (.).

Figure S2 (A) Serial dilution of BY4741, S288c, and YJM789 grown on YPD or YM+HULM with MCHM. (B) Reciprocal hemizygotes of Med15 in BY4741xYJM789 hybrids were grown on MCHM in YPD. Med15 was tagged at the chromosomal locus with 13xMyc at the C-terminal end or knockout with a dominant drug marker in haploid parents. Yeast was then mated, and diploids selected. An equal number of yeast were serially diluted and plated onto YPD with the indicated amount of MCHM. (C) BY4741 yeast (wildtype) and BY4741 med15::NatR (med15) were transformed with pGS35 (empty) or pGS35-MED15-Myc (pMED15 ${ }^{\text {YJM789 Myc }}$ 
and $\left.\mathrm{pMED} 15^{52889} \mathrm{Myc}\right)$. Plasmids were maintained with G418 in YPD and YM with glutamate (MSG) as the nitrogen source. Yeast was serially diluted and plated with indicated amounts of MCHM.

Figure S3 GO term analysis on genes that are downregulated in med15 mutants grown in YPD or YPD + 550 ppm MCHM compared to BY4741 and BY4741 expressing MED15 $15^{\text {YJM789 }}$ compared to BY4741 grown in YPD + 550 ppm MCHM.

Figure S4 GO term analysis on genes that are upregulated in med15 mutants grown in YPD or YPD + 550 ppm MCHM compared to BY4741, and BY4741 expressing MED15 YJM789 compared to BY4741 grown in YPD + 550 ppm MCHM.

Figure S5 Changes in the transcriptome of BY4741 yeast carrying different alleles of Med15 treated with MCHM grown in YM. (A) Differentially expressed mRNA from wildtype yeast (BY4741) compared to a med15 knockout strain grown in YPD. (B) Differentially expressed mRNA from wildtype yeast (BY4741) compared to a med15 knockout strain grown in YM then shifted to 550 ppm MCHM for 30 minutes. (C) Differentially expressed mRNA from wildtype yeast (BY4741) compared to a med15 knockout strain carrying Med15 $5^{\text {YJM789 }}$ expressed from a plasmid grown in YM then shifted to 650 ppm MCHM for 30 minutes. (D) Differentially expressed mRNA from wildtype yeast (BY4741) compared to a med15 knockout strain carrying Med15 $5^{\mathrm{S288c}}$ expressed from a plasmid grown in YM with G418 then shifted to 650 ppm MCHM for 30 minutes. 
Figure S6 GO term analysis on genes that are downregulated in med15 mutants grown in YM or YM + 650 ppm MCHM compared to BY4741.

Figure S7 GO term analysis on genes that are upregulated in med15 mutants grown in YM or YM + 650 ppm MCHM compared to BY4741, and BY4741 expressing MED15 ${ }^{\text {YJM789-Myc }}$ compared to BY4741 grown in YM + MCHM.

Figure S8 Overall of Med15/ MCHM regulated genes with SAGA or TFIID regulated genes. All genes are labelled depending on their SAGA/TFIID dominated status and whether there was overall with RNA-seq from Table S1.

Figure S9 Impact of hydrogen peroxide and MCHM on Med15 and Reactive Oxygen Species levels. (A) Western blot of Med15-Myc immunoprecipitated from BY4741 grown in YPD at 0, $10,20,40,60$ and 90 minutes after the addition of 550 ppm MCHM or $\mathrm{H}_{2} \mathrm{O}_{2}$. (B) Levels of ROS in strains of yeast exposed to MCHM, based on fluorescence of the ROS-reactive dye DHE. Yeast was incubated for 12 hours with or without MCHM then stained with DHE for 20 minutes before cells were sorted using flow cytometry. Hydrogen peroxide treatment for 1.5 hours was used as a positive control to generate ROS in wildtype (WT, BY4741) (black line) and med15 knockout yeast (grey line). Background ROS of untreated yeast in dark blue measures endogenous ROS compared med15 in light blue. MCHM WT yeast are in red while MCHM treated med15 yeast in orange. The $y$-axis represents the number of cells and the $x$ axis represents the fluorescence of DHE conversion to ethidium bromide by ROS. 
Figure S10 Changes in the transcriptome of BY4741 or yeast carrying or Med15 ${ }^{\mathrm{BY}}$

Med15 $5288 c$-Myc. (A) Differentially expressed mRNA from wildtype yeast (BY4741) compared to a med15 knockout with Med15 ${ }^{\text {S288c }}$-13xMyc strain grown in YPD. (B) Differentially expressed mRNA from wildtype yeast (BY4741) compared to a med15 knockout with Med15 ${ }^{\text {S288c }}$-Myc strain grown in YPD. (C) Serial dilution of BY4741 with Med15 ${ }^{\mathrm{BY}}$ or Med15 ${ }^{\mathrm{s} 288 \mathrm{c}}$ with and without the Myc tag.

Table S1 Differentially Expressed Gene list from BY4741, BY4741 med15::NAT (BYmed15), BY4741 med15::NAT with pMed15 YJM789-Myc (BYpMM_789), and BY4741 med15::NAT with pMed15 ${ }^{\text {S288c }}$-Myc (BYpMM_S288c) grown in YPD or YM with or without 550 ppm MCHM.

Table S2 Strain list.

Table S3 Primer list. All primers are listed $5^{\prime}$ to $3^{\prime}$ and the relative direction to MED15 is noted in the name. +/- notes the distance of the primer from the $5^{\prime}$ end of MED $15^{5288 c}$ or the junction of the genomic integration of the tag or the knockout cassette.

\section{REFERENCES}

Alberti, S., Halfmann, R., King, O., Kapila, A., and Lindquist, S. (2009). A systematic survey identifies prions and illuminates sequence features of prionogenic proteins. Cell 137, 146158.

Alberti, S., Gladfelter, A., and Mittag, T. (2019). Considerations and challenges in studying liquid-liquid phase separation and biomolecular condensates. Cell 176, 419-434. 
Albuquerque, C.P., Smolka, M.B., Payne, S.H., Bafna, V., Eng, J., and Zhou, H. (2008). A Multidimensional Chromatography Technology for In-depth Phosphoproteome Analysis. Mol Cell Proteomics 7, 1389-1396.

Anandhakumar, J., Moustafa, Y.W., Chowdhary, S., Kainth, A.S., and Gross, D.S. (2016). Evidence for Multiple Mediator Complexes in Yeast Independently Recruited by Activated Heat Shock Factor. Molecular and Cellular Biology 36, 1943-1960.

Ansari, S.A., Ganapathi, M., Benschop, J.J., Holstege, F.C.P., Wade, J.T., and Morse, R.H. (2011). Distinct role of Mediator tail module in regulation of SAGA-dependent, TATAcontaining genes in yeast. The EMBO Journal 31, 44-57.

Ayers, M.C., Sherman, Z.N., and Gallagher, J.E.G. (2020). Oxidative Stress Responses and Nutrient Starvation in MCHM Treated Saccharomyces cerevisiae. G3 (Bethesda) 10, 46654678.

Bähler, J., Wu, J.-Q., Longtine, M.S., Shah, N.G., Mckenzie III, A., Steever, A.B., Wach, A., Philippsen, P., and Pringle, J.R. (1998). Heterologous modules for efficient and versatile PCRbased gene targeting in Schizosaccharomyces pombe. Yeast 14, 943-951.

Baxendale, S., MacDonald, M.E., Mott, R., Francis, F., Lin, C., Kirby, S.F., James, M., Zehetner, G., Hummerich, H., and Valdes, J. (1993). A cosmid contig and high resolution restriction map of the 2 megabase region containing the Huntington's disease gene. Nat Genet 4, 181186.

Boehning, M., Dugast-Darzacq, C., Rankovic, M., Hansen, A.S., Yu, T., Marie-Nelly, H., McSwiggen, D.T., Kokic, G., Dailey, G.M., Cramer, P., et al. (2018). RNA polymerase II clustering through carboxy-terminal domain phase separation. Nature Structural \& Molecular Biology 25, 833-840.

Boija, A., Klein, I.A., Sabari, B.R., Dall'Agnese, A., Coffey, E.L., Zamudio, A. V., Li, C.H., Shrinivas, K., Manteiga, J.C., Hannett, N.M., et al. (2018). Transcription Factors Activate Genes through the Phase-Separation Capacity of Their Activation Domains. Cell 175, $1842-$ 1855.e16

Bourbon, H.-M. (2008). Comparative genomics supports a deep evolutionary origin for the large, four-module transcriptional mediator complex. Nucleic Acids Research 36, 39934008.

Brzovic, P.S., Heikaus, C.C., Kisselev, L., Vernon, R., Herbig, E., Pacheco, D., Warfield, L., Littlefield, P., Baker, D., Klevit, R.E., et al. (2011). The acidic transcription activator Gcn4 binds the Mediator subunit Gal11/Med15 using a simple protein interface forming a fuzzy complex. Mol Cell 44, 942-953.

Bun-Ya, M., Nishimura, M., Harashima, S., and Oshima, Y. (1991). The PHO84 gene of Saccharomyces cerevisiae encodes an inorganic phosphate transporter. Molecular and Cellular Biology 11, 3229-3238. 
Caplan, A.J., and Douglas, M.G. (1991). Characterization of YDJ1: a yeast homologue of the bacterial dnaJ protein. The Journal of Cell Biology 114, 609-621.

Cho, W.-K., Spille, J.-H., Hecht, M., Lee, C., Li, C., Grube, V., and Cisse, I.I. (2018). Mediator and RNA polymerase II clusters associate in transcription-dependent condensates. Science $361,412-415$.

Cooper, D.G., and Fassler, J.S. (2019). Med15: Glutamine-Rich Mediator Subunit with Potential for Plasticity. Trends in Biochemical Sciences.

Cozzarelli, I.M., Akob, D.M., Baedecker, M.J., Spencer, T., Jaeschke, J., Dunlap, D.S., Mumford, A.C., Poret-Peterson, A.T., and Chambers, D.B. (2017). Degradation of Crude 4MCHM (4-Methylcyclohexanemethanol) in Sediments from Elk River, West Virginia. Environmental Science \& Technology 51, 12139-12145.

Cui, D., Mebel, A.M., Arroyo-Mora, L.E., Holness, H., Furton, K.G., and O'Shea, K. (2017). Kinetic, product, and computational studies of the ultrasonic induced degradation of 4methylcyclohexanemethanol (MCHM). Water Research 126, 164-171.

Eastman, C. (2014). Eastman Crude MCHM Studies.

Evan, G.I., Lewis, G.K., Ramsay, G., and Bishop, J.M. (1985). Isolation of monoclonal antibodies specific for human c-myc proto-oncogene product. Molecular and Cellular Biology 5, 3610-3616.

Gallagher, J.E.G., and Baserga, S.J. (2004). Two-hybrid Mpp10p interaction-defective Imp4 proteins are not interaction defective in vivo but do confer specific pre-rRNA processing defects in Saccharomyces cerevisiae. Nucleic Acids Research 32, 1404-1413.

Gallagher, J.E.G., Zheng, W., Rong, X., Miranda, N., Lin, Z., Dunn, B., Zhao, H., and Snyder, M.P. (2014). Divergence in a master variator generates distinct phenotypes and transcriptional responses. Genes Dev 28, 409-421.

Gallagher, D.L., Phetxumphou, K., Smiley, E., and Dietrich, A.M. (2015). Tale of Two Isomers: Complexities of Human Odor Perception for cis- and trans-4-Methylcyclohexane Methanol from the Chemical Spill in West Virginia. Environ. Sci. Technol. 49, 1319-1327.

Giaever, G., Chu, A.M., Ni, L., Connelly, C., Riles, L., Veronneau, S., Dow, S., Lucau-Danila, A., Anderson, K., Andre, B., et al. (2002). Functional profiling of the Saccharomyces cerevisiae genome. Nature 418, 387-391.

Gillies, A.T., Taylor, R., and Gestwicki, J.E. (2012). Synthetic lethal interactions in yeast reveal functional roles of J protein co-chaperones. Molecular BioSystems 8, 2901-2908.

Gwinn, W.M., Bousquet, R.W., Perry, C.E., Urbano, N.C., and Auerbach, S.S. (2018). NTP Research Report on the Preliminary Evaluation of 4-Methylcyclohexylmethanol in an In Vitro Human Airway Model (National Toxicology Program).

Hahn, S. (2018). Phase Separation, Protein Disorder, and Enhancer Function. Cell 175, 17231725. 
Han, A.A., Fabyanic, E.B., Miller, J. V., Prediger, M.S., Prince, N., Mouch, J.A., and Boyd, J. (2017). In vitro cytotoxicity assessment of a West Virginia chemical spill mixture involving 4methylcyclohexanemethanol and propylene glycol phenyl ether. Environmental Monitoring and Assessment 189, 190.

Hayes, M.H., Peuchen, E.H., Dovichi, N.J., and Weeks, D.L. (2018). Dual roles for ATP in the regulation of phase separated protein aggregates in Xenopus oocyte nucleoli. ELife 7 , e35224.

He, Q., Battistella, L., and Morse, R.H. (2008). Mediator requirement downstream of chromatin remodeling during transcriptional activation of CHA1 in yeast. Journal of Biological Chemistry 283, 5276-5286.

Hedbacker, K., and Carlson, M. (2008). SNF1/AMPK pathways in yeast. Front Biosci 13, 2408-2420.

Herbig, E., Warfield, L., Fish, L., Fishburn, J., Knutson, B.A., Moorefield, B., Pacheco, D., and Hahn, S. (2010). Mechanism of Mediator Recruitment by Tandem Gcn4 Activation Domains and Three Gal11 Activator-Binding Domains. Mol Cell Biol 30, 2376-2390.

Hines, J.K., Li, X., Du, Z., Higurashi, T., Li, L., and Craig, E.A. (2011). [SWI], the prion formed by the chromatin remodeling factor Swi1, is highly sensitive to alterations in Hsp70 chaperone system activity. PLoS Genetics 7, e1001309.

Holt, L.J., Tuch, B.B., Villén, J., Johnson, A.D., Gygi, S.P., and Morgan, D.O. (2009). Global analysis of Cdk1 substrate phosphorylation sites provides insights into evolution. Science 325, 1682.

Horzmann, K.A., de Perre, C., Lee, L.S., Whelton, A.J., and Freeman, J.L. (2017). Comparative analytical and toxicological assessment of methylcyclohexanemethanol (MCHM) mixtures associated with the Elk River chemical spill. Chemosphere 188, 599-607.

Hsu, J., Del Rosario, M.C., Thomasson, E., Bixler, D., Haddy, L., and Duncan, M.A. (2017). Hospital Impact after a Chemical Spill That Compromised the Potable Water Supply: West Virginia, January 2014. Disaster Medicine and Public Health Preparedness 11, 621-624.

Huisinga, K.L., and Pugh, B.F. (2004). A genome-wide housekeeping role for TFIID and a highly regulated stress-related role for SAGA in Saccharomyces cerevisiae. Molecular Cell 13, 573-585.

Hyman, A.A., Weber, C.A., and Ulicher, F.J." (2014). Downloaded from www.annualreviews.org Access provided by West Virginia University on 05/17/19. For personal use only. Annu. Rev. Cell Dev. Biol 30, 39-58.

Island, M.D., Perry, J.R., Naider, F., and Becker, J.M. (1991). Isolation and characterization of S. cerevisiae mutants deficient in amino acid-inducible peptide transport. Current Genetics 20, 457-463. 
Jedidi, I., Zhang, F., Qiu, H., Stahl, S.J., Palmer, I., Kaufman, J.D., Nadaud, P.S., Mukherjee, S., Wingfield, P.T., Jaroniec, C.P., et al. (2010). Activator Gcn4 employs multiple segments of Med15/Gal11, including the KIX domain, to recruit mediator to target genes in vivo. J Biol Chem 285, 2438-2455.

Jeronimo, C., and Robert, F. (2014). Kin 28 regulates the transient association of Mediator with core promoters. Nature Structural and Molecular Biology 21, 449-455.

Kachroo, A.H., Laurent, J.M., Yellman, C.M., Meyer, A.G., Wilke, C.O., and Marcotte, E.M. (2015). Systematic humanization of yeast genes reveals conserved functions and genetic modularity. Science 348, 921-925.

Kang, J., Lim, L., and Song, J. (2018). ATP enhances at low concentrations but dissolves at high concentrations liquid-liquid phase separation (LLPS) of ALS/FTD-causing FUS. Biochem Biophys Res Commun 504, 545-551.

Korber, P., and Barbaric, S. (2014). The yeast PHO5 promoter: From single locus to systems biology of a paradigm for gene regulation through chromatin. Nucleic Acids Research 42, 10888-10902.

Krobitsch, S., and Lindquist, S. (1999). Aggregation of huntingtin in yeast varies with the length of the polyglutamine expansion and the expression of chaperone proteins. Proceedings of the National Academy of Sciences 97, 1589-1594.

Lan, J., Hu, M., Gao, C., Alshawabkeh, A., and Gu, A.Z. (2015). Toxicity Assessment of 4Methyl-1-cyclohexanemethanol and Its Metabolites in Response to a Recent Chemical Spill in West Virginia, USA. Environ Sci Technol 49, 6284-6293.

Landles, C., and Bates, G.P. (2004). Huntingtin and the molecular pathogenesis of Huntington's disease. EMBO Reports 5, 958-963.

Larsson, M., Uvell, H., Sandstrom, J., Ryden, P., Selth, L.A., and Bjorklund, S. (2013). Functional studies of the yeast med5, med15 and med16 mediator tail subunits. PLoS One 8 , e73137

Lin, Y., Protter, D.S.W., Rosen, M.K., and Parker, R. (2015). Formation and Maturation of Phase-Separated Liquid Droplets by RNA-Binding Proteins. Mol Cell 60, 208-219.

Mara, P., Fragiadakis, G.S., Gkountromichos, F., and Alexandraki, D. (2018). The pleiotropic effects of the glutamate dehydrogenase (GDH) pathway in Saccharomyces cerevisiae. Microbial Cell Factories 17, 170.

Martin Schmidt (2019) University of Pittsburgh, Pittsburgh, USA. Pers. Commun.

Martinez, P., and Persson, B.L. (1998). Identification, cloning and characterization of a derepressible $\mathrm{Na}+$-coupled phosphate transporter in Saccharomyces cerevisiae. Molecular and General Genetics 258, 628-638. 
Michelitsch, M.D., and Weissman, J.S. (2000). A census of glutamine/asparagine-rich regions: Implications for their conserved function and the prediction of novel prions. Proceedings of the National Academy of Sciences of the United States of America 97, 11910-11915.

Miller, C., Matic, I., Maier, K.C., Schwalb, B., Roether, S., Strässer, K., Tresch, A., Mann, M., and Cramer, P. (2012). Mediator Phosphorylation Prevents Stress Response Transcription During Non-stress Conditions. Journal of Biological Chemistry 287, 44017-44026.

Muchowski, P.J., Schaffar, G., Sittler, A., Wanker, E.E., Hayer-Hartl, M.K., and Hartl, F.U. (2000). Hsp70 and hsp40 chaperones can inhibit self-assembly of polyglutamine proteins into amyloid-like fibrils. Proceedings of the National Academy of Sciences of the United States of America 97, 7841-7846.

Pacheco, D., Warfield, L., Brajcich, M., Robbins, H., Luo, J., Ranish, J., and Hahn, S. (2018). Transcription Activation Domains of the Yeast Factors Met4 and Ino2: Tandem Activation Domains with Properties Similar to the Yeast Gcn4 Activator. Molecular and Cellular Biology 38, e00038-18.

Patel, A., Malinovska, L., Saha, S., Wang, J., Alberti, S., Krishnan, Y., and Hyman, A.A. (2017). ATP as a biological hydrotrope. Science $356,753-756$.

Paustenbach, D.J., Winans, B., Novick, R.M., and Green, S.M. (2015). The toxicity of crude 4methylcyclohexanemethanol (MCHM): review of experimental data and results of predictive models for its constituents and a putative metabolite. Crit Rev Toxicol 45 Suppl 2, 1-55.

Phetxumphou, K., Dietrich, A.M., Shanaiah, N., Smiley, E., and Gallagher, D.L. (2016). Subtleties of human exposure and response to chemical mixtures from spills. Environmental Pollution 214, 618-626.

Poss, Z.C., Ebmeier, C.C., and Taatjes, D.J. (2013). The Mediator complex and transcription regulation. Critical Reviews in Biochemistry and Molecular Biology 48, 575-608

Pupo, A., Ayers, M.C., Sherman, Z.N., Vance, R.J., Cumming, J.R., and Gallagher, J.E.G.G. (2019b). MCHM Acts as a Hydrotrope, Altering the Balance of Metals in Yeast. Biological Trace Element Research 1-12.

Pupo, A., Ku, K.M., and Gallagher, J.E.G. (2019c). Effects of MCHM on yeast metabolism. PLOS ONE 14.

Qiu, H., Chereji, R. V, Hu, C., Cole, H.A., Rawal, Y., Clark, D.J., and Hinnebusch, A.G. (2016). Genome-wide cooperation by HAT Gcn5, remodeler SWI/SNF, and chaperone Ydj1 in promoter nucleosome eviction and transcriptional activation. Genome Research 26, 211225.

Read, T., Richmond, P.A., Dowell, R.D., Félix, M., Bentley, D., and Chakravarti, A. (2016). A trans-acting Variant within the Transcription Factor RIM101 Interacts with Genetic Background to Determine its Regulatory Capacity. PLOS Genetics 12, e1005746. 
Robinson, P.J., Trnka, M.J., Pellarin, R., Greenberg, C.H., Bushnell, D.A., Davis, R., Burlingame, A.L., Sali, A., and Kornberg, R.D. (2015). Molecular architecture of the yeast Mediator complex. ELife 4, e08719.

Rong-Mullins, X., Winans, M.J., Lee, J.B., Lonergan, Z.R., Pilolli, V.A., Weatherly, L.M., Carmenzind, T.W., Jiang, L., Cumming, J.R., Oporto, G.S., et al. (2017). Proteomic and genetic analysis of the response of $\mathrm{S}$. cerevisiae to soluble copper leads to improvement of the antimicrobial function of cellulosic copper nanoparticles. Metallomics 9, 1304-1315.

Rong-Mullins, X., Ayers, M.C., Summers, M., and Gallagher, J.E.G. (2018). Transcriptional Profiling of Saccharomyces cerevisiae Reveals the Impact of Variation of a Single Transcription Factor on Differential Gene Expression in 4NQO, Fermentable, and Nonfermentable Carbon Sources. G3: Genes, Genomes, Genetics 8.

Sabari, B.R., Dall'Agnese, A., Boija, A., Klein, I.A., Coffey, E.L., Shrinivas, K., Abraham, B.J., Hannett, N.M., Zamudio, A. V., Manteiga, J.C., et al. (2018). Coactivator condensation at super-enhancers links phase separation and gene control. Science 361, eaar3958.

Serra-Cardona, A., Petrezselyova, S., Canadell, D., Ramos, J., and Arino, J. (2014). Coregulated Expression of the Na+/Phosphate Pho89 Transporter and Ena1 Na+-ATPase Allows Their Functional Coupling under High-pH Stress. Molecular and Cellular Biology 34, 4420-4435.

Shao, D., Creasy, C.L., and Bergman, L.W. (1996). Interaction of Saccharomyces cerevisiae Pho2 with Pho4 increases the accessibility of the activation domain of Pho4. Molecular \& General Genetics : MGG 251, 358-364.

Shao, D., Creasy, C.L., and Bergman, L.W. (1998). A cysteine residue in helix II of the bHLH domain is essential for homodimerization of the yeast transcription factor Pho4p.

Simpson-Lavy, K., and Kupiec, M. (2018). A reversible liquid drop aggregation controls glucose response in yeast. Current Genetics 64, 785-788.

Song, G., Dickins, B.J., Demeter, J., Engel, S., Gallagher, J., Choe Barbara., K.D., and Cherry, J.M. (2015). AGAPE (Automated Genome Analysis PipelinE) for pan-genome analysis of Saccharomyces cerevisiae. PloS One 10, e0120671.

Soulard, A., Cremonesi, A., Moes, S., Schütz, F., Jenö, P., and Hall, M.N. (2010). The Rapamycin-sensitive Phosphoproteome Reveals That TOR Controls Protein Kinase A Toward Some But Not All Substrates. Molecular Biology of the Cell 21, 3475-3486.

Summers, D.W., Douglas, P.M., Ren, H.-Y., and Cyr, D.M. (2009). The type I Hsp40 Ydj1 utilizes a farnesyl moiety and zinc finger-like region to suppress prion toxicity. The Journal of Biological Chemistry 284, 3628-3639.

Swaney, D.L., Beltrao, P., Starita, L., Guo, A., Rush, J., Fields, S., Krogan, N.J., Villén, J., and Villen, J. (2013). Global analysis of phosphorylation and ubiquitylation cross-talk in protein degradation. Nat Methods 10, 676-682. 
Thomasson, E.D., Scharman, E., Fechter-Leggett, E., Bixler, D., Ibrahim, S., Duncan, M.A., Hsu, J., Scott, M., Wilson, S., Haddy, L., et al. (2017). Acute Health Effects After the Elk River Chemical Spill, West Virginia, January 2014. Public Health Rep 132, 196-202.

Tsai, K.L., Tomomori-Sato, C., Sato, S., Conaway, R.C., Conaway, J.W., and Asturias, F.J. (2014). Subunit architecture and functional modular rearrangements of the transcriptional mediator complex. Cell 157, 1430-1444.

Tuttle, L.M., Pacheco, D., Warfield, L., Luo, J., Ranish, J., Hahn, S., and Klevit, R.E. (2018). Gcn4-Mediator Specificity Is Mediated by a Large and Dynamic Fuzzy Protein-Protein Complex. Cell Reports 22, 3251-3264.

Uthe, H., Vanselow, J.T., and Schlosser, A. (2017). Proteomic Analysis of the Mediator Complex Interactome in Saccharomyces cerevisiae. Scientific Reports 7.

Vandenbol, M., Jauniaux, J.C., and Grenson, M. (1989). Nucleotide sequence of the Saccharomyces cerevisiae PUT4 proline-permease-encoding gene: similarities between CAN1, HIP1 and PUT4 permeases. Gene 83, 153-159.

Verger, A., Monté, D., and Villeret, V. (2019). Twenty years of Mediator complex structural studies. Biochemical Society Transactions 47, 399-410.

Villers, J., Savocco, J., Szopinska, A., Degand, H., Nootens, S., and Morsomme, P. (2017). Study of the Plasma Membrane Proteome Dynamics Reveals Novel Targets of the Nitrogen Regulation in Yeast. Molecular \& Cellular Proteomics : MCP 16, 1652-1668.

Warfield, L., Tuttle, L.M., Pacheco, D., Klevit, R.E., and Hahn, S. (2014). A sequence-specific transcription activator motif and powerful synthetic variants that bind Mediator using a fuzzy protein interface. PNAS 111, E3506-E3513.

Wang, Y., Weisenhorn, E., MacDiarmid, C.W., Andreini, C., Bucci, M., Taggart, J., Banci, L., Russell, J., Coon, J.J., and Eide, D.J. (2018). The cellular economy of the Saccharomyces cerevisiae zinc proteome. Metallomics 10, 1755-1776.

Weidhaas, J., Lin, L.-S., Buzby, K., and Li, X. (2016). Biodegradation of MCHM and PPH in River Microcosms and Activated Sludge. Journal of Environmental Engineering 142, 04016056.

Yu, G., Wang, L.-G., Han, Y., and He, Q.-Y. (2012). clusterProfiler: An R Package for Comparing Biological Themes Among Gene Clusters. OMICS: A Journal of Integrative Biology 16, 284-287.

Zhang, F., Sumibcay, L., Hinnebusch, A.G., and Swanson, M.J. (2004). A triad of subunits from the Gal11/tail domain of Srb mediator is an in vivo target of transcriptional activator Gcn4p. Molecular and Cellular Biology 24, 6871-6886.

Zhu, X., Chen, L., Carlsten, J.O.P., Liu, Q., Yang, J., Liu, B., and Gustafsson, C.M. (2015). Mediator tail subunits can form amyloid-like aggregates in vivo and affect stress response in yeast. Nucleic Acids Research 43, 7306-7314. 


\section{CHAPTER 4: PROXIMITY LABELLING OF MED15 TO DETERMINE ITS INTERACTIONS}

*In Progress

\section{ABSTRACT}

As part of the pre-initiation complex (PIC), the Mediator acts as a bridge between DNA binding transcription factors and RNA polymerase II and serves as an endpoint for signaling pathways. Found within the tail domain of the Mediator is Med15, a subunit often recruited by stress-induced transcription factors. The genetic variations within the polyQ tracts of Med15 were responsible for the different growth responses observed when yeast cells were exposed to a diverse range of stressors. PolyQ tracts, kinase inducible domain, and activator binding domains of Med15 are known targets of transcription factors like Pho4, Ino2, and Pdr1. Protein-protein interactions are an essential part of most cellular processes and biological networks. Therefore, we were particularly interested in investigating other interactions that Med15 has with other kinases and Mediator subunits. The proposed method to detect these weak and transient interactions started with Myc purifications and then moved to TurbolD, proximity labeling. TurbolD is a much more efficient technique with short labeling time and robust biotinylation. Med15 in BY4741 has been successfully TurbolD-tagged and will be used to investigate Med15 interactions further.

\section{INTRODUCTION}

The Mediator is a global regulator of gene expression and is considered part of the PIC complex (Ansari et al., 2009; Poss et al., 2013). It forms a bridge by relaying signals from transcription factors to RNA pol II and ultimately serves as an endpoint for transcription 
signaling pathways (Takagi and Kornberg, 2006; Taatjes and Tjian, 2004). The Mediator does not only serve as a cofactor for activator-dependent transcriptions but also encourages basal transcription and plays a role through all stages of a cell's transcription cycle (Hantsche and Cramer, 2017). The Mediator's fairly large and flexible conformational structure contributes to its functional versatility. Mediator isolated from S. cerevisiae has a total molecular mass of 1.4 MDa and comprises 25 subunits organized into 4 modules: head, middle, tail, and kinase domains (Harper and Taatjes, 2018). Recent studies argue that the position of these modules is not as suggested before, where the head and the tail module were at opposite ends of each other, with the middle module connecting them like a bridge. Instead, high-resolution EM studies have shown that the head and middle module form the center of the complex while the tail is positioned at the end of the complex (Cai et al., 2009; Tsai et al., 2013). The head module interacts with the C-terminal domain of RNA pol II, while the middle module deals with cyclin-dependent kinases (CDKs). The tail works with specific regulatory factors and is responsible for the recruitment of the Mediator to the DNA (Allen and Taatjes, 2015; Verger et al., 2019).

Within the tail of the Mediator lies five subunits: Med15, Med2, Med3, Med5, and Med16 (Robinson et al., 2015; Tsai et al., 2014). In humans, loss of one copy of the Med15 causes DiGeorge syndrome, where the individual suffers from severe congenital issues with neurocranial developmental defects (McDonald-McGinn et al., 2015). The presence of Med15 is considered not essential for the viability of yeast cells under normal environmental conditions. However, when yeast cells experience a drastic change in their environments, such as temperature change or exposure to a chemical, Med15 is vital for survival (Gallagher et al., 2020). This highly conserved subunit interacts directly with stress- 
induced transcription factors and is heavily phosphorylated under non-stress conditions (Miller et al., 2012). Some of the transcription factors that are known to interact with Med15 include Pdr1 (a transcription factor that regulates pleiotropic drug response), Oaf1 (Oleate-activated transcription factor that senses fatty acid levels), Pho4 (a basic helix-loophelix transcription factor of the myc family), and Ino2 (a transcription factor involved in inositol response) (Miller et al., 2012). The interactions between Med15 and these transcription factors have been well studied and well characterized.

With our current knowledge of the Mediator complex and Med15, we wanted to investigate further interactions that Med15 has that have not been discovered, particularly interactions with kinases and other subunits within the Mediator complex itself. This would shed light on the other pathways that Med15 is involved in and also add to our current knowledge about its function. We proposed tagging Med15 with a proximity labeling tag called TurbolD and isolating the subunit, which will allow for the pulldown of any closely associating proteins that physically interact with Med15. These proteins will then undergo a digestion step typically using trypsin, and the resulting peptide fragments will be analyzed using massspectrometry-based proteomics.

In the past decade or so, researchers relied on traditional approaches such as yeast-twohybrid and affinity purification to study protein-protein interactions (Brückner et al., 2009; Dunham et al., 2012). Affinity purification coupled with mass-spectrometry-based proteomics allows only for stable interacting proteins that are soluble to be analyzed. Weak or transient interactions are often eliminated during cell lysis and subsequent washing processes (Qin et al., 2021). Although yeast-two-hybrid allows for high-throughput 
screening, this method also produces a high rate of false positives and negatives. False positives can occur due to over-expression and self-activation of the bait (our protein of interest) and prey (unknown closely associating partner)(Mehla et al., 2017). On the other hand, false negatives tend to happen because of protein misfolding or geometric constraints of the protein tags (Knudsen et al., 2002).

Proximity labeling was then developed as an alternative to address the limitations and disadvantages of these traditional approaches. Proximity labeling is a powerful tool used for tagging endogenous interaction partners of any protein of interest. Engineered enzymes catalyze the conversion of a small substrate into a highly reactive intermediate that eventually diffuses out from the enzyme's active site to covalently tag endogenous biomolecules in close proximity (Cho et al., 2020; Qin et al., 2021). TurbolD, developed in the Ting Lab at Stanford University, is an engineered biotin ligase that uses ATP to convert biotin into biotin-AMP (intermediate), which then labels any protein within a proximal distance (Branon et al., 2018). As a result, there is a much shorter labeling time with higher efficiency for TurbolD compared to other labeling techniques like BiolD (Qin et al., 2021). Yeast, plants, D. melanogaster, and C. elegans are just some of the model organisms in which TurbolD have been used (Cho et al., 2020; Mair et al., 2019).

Here we decided to also look into the influence of Med15's genetic variations on the protein it chooses to interact and associate with. As seen earlier in my thesis, the difference in MCHM tolerance and growth phenotype suggests that Med15 associates itself with different kinases and Mediator subunits depending on its genetic makeup. The insights from this proximity labeling technique are useful for the field of yeast genetics and protein- 
protein interactions. This chapter will discuss the preliminary approach of analyzing the post-translational modifications of Med15 (YJM789 and S288c) using an antibody pulldown of the myc-tagged Med15 to determine if this approach was sufficient for massspectrometry analysis.

\section{MATERIALS AND METHODS}

\section{Yeast Strains and Growth Media (Antibody Pulldown Analysis)}

For the antibody pulldown analysis part of the experiment, Med15 myc-tagged strains that were constructed for the paper in Chapter 3 were utilized (Gallagher et al., 2020). All strains and sources are listed below in Table 1. Med15 sequences were extracted from the sequenced genomes of YJM789 and S288c. Med15 was tagged at the C-terminus with a 13xMyc tag, with KanR as the selectable marker in S288c and YJM789 (Gallagher et al., 2014). PCR product of the amplified MED15 including the promoter, coding region, Myc tag and KanR marker were cloned into the Notl restriction site in pRS316. The cloned plasmids containing different alleles of MED15 were transformed into BY4741 med15 yeast, and transformants were selected on YPD with G418. All yeast strains were grown in nutrient rich media (YPD) containing $1 \%$ yeast extract, $2 \%$ peptone and $2 \%$ dextrose. Yeasts were grown in liquid media to mid-log phase and plasmids were maintained with the addition of 0.5 $\mathrm{mg} / \mathrm{ml} \mathrm{G} 418$. 
Table 1: Strain List

\begin{tabular}{|c|c|c|c|c|}
\hline & Name & Background & Specific Genotype & Source \\
\hline 1 & BY4741 & BY4741 & $\begin{array}{l}\text { MATa, his } 3 \Delta 0, \text { ura3 } \Delta 0, \operatorname{leu} 2 \Delta 0, \\
\operatorname{met} 15 \Delta 0\end{array}$ & $\begin{array}{l}\text { (Brachmann et al., } \\
\text { 1998) }\end{array}$ \\
\hline 2 & S288c & S288c & MATa (also known as GSY147) & (Kao et al., 2010) \\
\hline 3 & YJM789K5a & YJM789 & MATa ho::HisG LYS2 & $\begin{array}{l}\text { (Rong-Mullins et } \\
\text { al., 2017) }\end{array}$ \\
\hline 4 & $\begin{array}{l}\text { BY4741 wildtype } \\
\text { empty }\end{array}$ & BY4741 & pGS35 & this study \\
\hline 5 & $\begin{array}{l}\text { BY4741 } \\
\text { med15 } \Delta \text { empty }\end{array}$ & BY4741 & pGS35, med15 $5^{B Y}::$ NatR & this study \\
\hline 6 & $\begin{array}{l}\text { BY4741 MED15 } 5^{\text {S288c }} \\
\text { Myc }\end{array}$ & BY4741 & $\begin{array}{l}\operatorname{med} 15^{B Y}:: \text { NatR pMED15 } 5^{Y J M 789} \text {-Myc } \\
\text { (pGS35 with KanR, URA3) }\end{array}$ & this study \\
\hline 7 & $\begin{array}{l}\text { BY4741 MED15 } \\
\text { MyC }\end{array}$ & BY4741 & $\begin{array}{l}\operatorname{med} 15^{B Y}:: \text { NatR pMED15 } 5^{Y J M 789} \text {-Myc } \\
\text { (KanR, URA3) }\end{array}$ & this study \\
\hline 8 & $\begin{array}{l}\text { BY4741 MED15- } \\
\text { TurbolD }\end{array}$ & BY4741 & MED15-TurbolD (NatR) & This study \\
\hline
\end{tabular}

\section{Western Blot}

Proteins were extracted and immunoprecipitated using the anti-Myc monoclonal antibody.

A phosphatase assay using the NEB's Lambda Protein Phosphatase (Lambda PP) was then conducted on the protein bound beads for dephosphorylation. Proteins were then separated in 5\%-12\% SDS-PAGE and then transferred onto 0.2 micron PVDF, as previously described (Gallagher et al., 2020). Antibodies (mouse anti-Myc E910 $(1: 7,500)$ and rabbit 
anti-PGK $(1: 10,000))$ were diluted into 3\% BSA Fraction V in TBS-Tween. ECL kit and HRP secondary antibodies were used to visualize the blot on a Protein Simple using the default chemiluminescence setting.

\section{Silver Stain}

Proteins were extracted and immunoprecipitated. A phosphatase assay using NEB's Lambda Protein Phosphatase (Lambda PP) was then conducted on the protein bound beads for dephosphorylation. Proteins were then separated in 5\%-12\% SDS-PAGE and the gel was then silver stained using the BioRad Silver Stain Plus kit. The gel was destained with several washes of $1 \%$ hydrogen peroxide before 6 specific bands per sample lane were cut up for mass spectrometry analysis.

\section{TurbolD Strain Development and Growth Media}

PCR amplification of the TurbolD tag from pFA6a-TurbolD-3MYC-natMX6 (pFB1434) (Larochelle et al., 2019) were transformed into BY4741 (MATa, his3 $\Delta 0$, ura3 $\Delta 0$, leu2 $\Delta 0$, met15 $\Delta 0$ ). The transformants were selected on YPD with Nat. Three successful transformant colonies were verified via PCR using check primers. BY4741 was grown in nutrient rich media (YPD) containing $1 \%$ yeast extract, $2 \%$ peptone and $2 \%$ dextrose. Yeasts were grown in liquid media to mid-log phase.

\section{RESULTS}

To maintain consistency with previous studies, we used the myc tag to pull down Med15 and associated proteins. However, no obvious bands were produced for either the western 
blot or the silver staining experiment for the myc-antibody pulldown of Med15 for both the alleles (YJM789 and S288c) (Figure 1). Despite various changes made to the protein extraction and immunoprecipitation protocol, images of the developed western blot gels were relatively poor. They showed bands smearing instead of the clear, separate bands that were expected. The silver staining technique yields a very similar result with no significant differences in the banding between each sample. Mass spectrometry analysis of the digested protein lysates produced no results as well, with no protein detected.

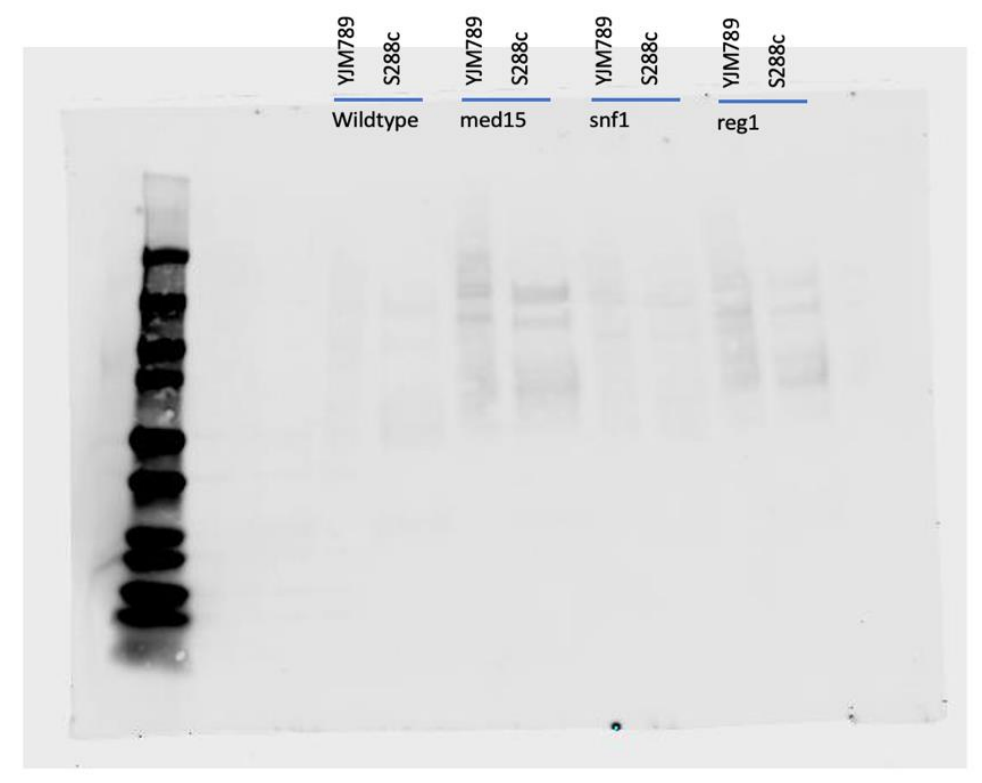

Figure 1. Western blot of YJM789 or S288c alleles of Med15-Myc immunoprecipitated from BY4741 grown in YPD with SNF1 and REG1 deleted. The western blot was conducted after the protein bound beads were subjected to a phosphatase assay.

\section{DISCUSSION}

Because the technique of using a myc-antibody pulldown failed to produce any substantial results, the proximity labeling technique using TurbolD would be the next best step.

Bradford assays conducted on protein lysates indicated a significant amount of protein prior to the immunoprecipitation step. The inability to detect any protein in both the mass spectrometry analysis and western blots suggests that most of the proteins might have been lost during the immunoprecipitation step, or the background was too high and swamped out the signal. With TurbolD, streptavidin-conjugated beads, which are commonly used for 
the enrichment of biotin-tagged molecules, have a much better binding capacity (Berg Luecke and Gundry, 2021; Branon et al., 2018). Studies that have compared TurbolD with other labeling techniques found that TurbolD had a lower rate of data contamination with a robust level of biotinylation to overcome low levels of protein expression (Cho et al., 2020; May et al., 2020). So, even if the absence of bands in both the western blots and silver staining technique were due to low expressions of Med15, the use of TurbolD would help overcome that as well as starting with more material. So far, strain making of a TurbolD tagged Med15 for BY4741 has been completed. From here, we can proceed with the rest of the protocol. First, we expect to see a drastic improvement in the quality of our results with more apparent bands and detection of Med15 in the mass spectrometry analysis. Second, we expect to find Med15 interacting with new transcription factors, kinases, and other Mediator subunits. With this new efficient technique, Med15 associated partners and the pathway that it helps to regulate can be identified.

\section{REFERENCES}

Allen, B.L., and Taatjes, D.J. (2015). The Mediator complex: a central integrator of transcription. Nat Rev Mol Cell Biol 16, 155-166.

Ansari, S.A., Ganapathi, M., Benschop, J.J., Holstege, F.C.P., Wade, J.T., and Morse, R.H. (2011). Distinct role of Mediator tail module in regulation of SAGA-dependent, TATAcontaining genes in yeast. The EMBO Journal 31, 44-57.

Berg Luecke, L., and Gundry, R.L. (2021). Assessment of Streptavidin Bead Binding Capacity to Improve Quality of Streptavidin-based Enrichment Studies. J. Proteome Res. 20, 11531164. 
Branon, T.C., Bosch, J.A., Sanchez, A.D., Udeshi, N.D., Svinkina, T., Carr, S.A., Feldman, J.L., Perrimon, N., and Ting, A.Y. (2018). Efficient proximity labeling in living cells and organisms with TurbolD. Nat Biotechnol 36, 880-887.

Brückner, A., Polge, C., Lentze, N., Auerbach, D., and Schlattner, U. (2009). Yeast TwoHybrid, a Powerful Tool for Systems Biology. Int J Mol Sci 10, 2763-2788.

Cai, G., Imasaki, T., Takagi, Y., and Asturias, F.J. (2009). Mediator Structural Conservation and Implications for the Regulation Mechanism. Structure 17, 559-567.

Cho, W.-K., Spille, J.-H., Hecht, M., Lee, C., Li, C., Grube, V., and Cisse, I.I. (2018). Mediator and RNA polymerase II clusters associate in transcription-dependent condensates. Science $361,412-415$.

Dunham, W.H., Mullin, M., and Gingras, A.-C. (2012). Affinity-purification coupled to mass spectrometry: basic principles and strategies. Proteomics 12, 1576-1590.

Gallagher, J.E.G., Ser, S.L., Ayers, M.C., Nassif, C., and Pupo, A. (2020). The Polymorphic PolyQ Tail Protein of the Mediator Complex, Med15, Regulates the Variable Response to Diverse Stresses. International Journal of Molecular Sciences 21, 1894

Hantsche, M., and Cramer, P. (2017). Conserved RNA polymerase II initiation complex structure. Curr Opin Struct Biol 47, 17-22.

Harper, T.M., and Taatjes, D.J. (2018). The complex structure and function of Mediator. J Biol Chem 293, 13778-13785.

Knudsen, C.R., Jadidi, M., Friis, I., and Mansilla, F. (2002). Application of the yeast two-hybrid system in molecular gerontology. Biogerontology 3, 243-256. 
Larochelle, M., Bergeron, D., Arcand, B., and Bachand, F. (2019). Proximity-dependent biotinylation mediated by TurbolD to identify protein-protein interaction networks in yeast. Journal of Cell Science 132.

Mair, A., Xu, S.-L., Branon, T.C., Ting, A.Y., and Bergmann, D.C. (2019). Proximity labeling of protein complexes and cell-type-specific organellar proteomes in Arabidopsis enabled by TurbolD. ELife 8, e47864.

May, D.G., Scott, K.L., Campos, A.R., and Roux, K.J. (2020). Comparative Application of BiolD and TurbolD for Protein-Proximity Biotinylation. Cells 9.

Mehla, J., Caufield, J.H., Sakhawalkar, N., and Uetz, P. (2017). A comparison of two hybrid approaches for detecting protein-protein interactions. Methods Enzymol 586, 333-358.

Miller, C., Matic, I., Maier, K.C., Schwalb, B., Roether, S., Strässer, K., Tresch, A., Mann, M., and Cramer, P. (2012). Mediator Phosphorylation Prevents Stress Response Transcription During Non-stress Conditions. Journal of Biological Chemistry 287, 44017-44026.

McDonald-McGinn, D.M., Sullivan, K.E., Marino, B., Philip, N., Swillen, A., Vorstman, J.A.S., Zackai, E.H., Emanuel, B.S., Vermeesch, J.R., Morrow, B.E., et al. (2015). 22q11.2 deletion syndrome. Nat Rev Dis Primers 1, 15071.

Poss, Z.C., Ebmeier, C.C., and Taatjes, D.J. (2013). The Mediator complex and transcription regulation. Critical Reviews in Biochemistry and Molecular Biology 48, 575-608.

Qin, W., Cho, K.F., Cavanagh, P.E., and Ting, A.Y. (2021). Deciphering molecular interactions by proximity labeling. Nat Methods 18, 133-143. 
Robinson, P.J., Trnka, M.J., Pellarin, R., Greenberg, C.H., Bushnell, D.A., Davis, R., Burlingame, A.L., Sali, A., and Kornberg, R.D. (2015). Molecular architecture of the yeast Mediator complex. ELife 4, e08719.

Taatjes, D.J., and Tjian, R. (2004). Structure and function of CRSP/Med2; a promoterselective transcriptional coactivator complex. Mol Cell 14, 675-683.

Takagi, Y., and Kornberg, R.D. (2006). Mediator as a General Transcription Factor *. Journal of Biological Chemistry 281, 80-89.

Tsai, K.L., Tomomori-Sato, C., Sato, S., Conaway, R.C., Conaway, J.W., and Asturias, F.J. (2014). Subunit architecture and functional modular rearrangements of the transcriptional mediator complex. Cell 157, 1430-1444.

Verger, A., Monté, D., and Villeret, V. (2019). Twenty years of Mediator complex structural studies. Biochemical Society Transactions 47, 399-410. 


\section{CHAPTER 5: CONCLUSION}

Being placed in a stressful environmental condition can trigger a cascade of stress response pathways. The capacity of genetic reprogramming by decreasing the expression of housekeeping genes and enhancing the expression of stress-encoded genes may lead to physiological changes that promote an organism's survival following the Elk River spill in 2014, many residents in Charleston, West Virginia, reported mild skin irritation, nauseousness, and gastrointestinal issues (Foreman et al., 2015). The lack of knowledge regarding the coal cleaning chemical MCHM (4-methylcyclohexanemethanol) prompted extensive studies about its toxicological effects and physical properties. Although in the five years after the spill, there were no significant health effects on babies born to pregnant mothers during the spill (Benson et al., 2018), studies in the lab have shown that Xenopus embryos suffered from developmental effects with reversible paralysis (Perfetto et al., 2020). Interestingly, the hydrotropic characteristic of MCHM is known to prevent protein aggregation by contributing to liquid-liquid phase separation (LLPS) (Pupo et al., 2020). This thesis emphasizes the use of MCHM as a novel hydrotropic stressor and how it affects the stress response pathway in yeast through Med15, a subunit in the Mediator complex.

In Chapter 3, the data has shown that the genetic variation between two Med15 alleles (YJM789 and S288c) had significant differences in stress response when exposed to MCHM and other chemical stressors. The two polymorphic polyQ tracts (polyQI and poly QII) that vary between 12 and 27 glutamine repeats between strains, as suspected, played a role in cell growth when exposed to MCHM. When polyQ domains of Med15 $5^{\mathrm{YJM} 789}$ were swapped for those with Med15 $5288 c$, cell growth improved even in the presence of MCHM. This was possibly due to the hydrotropic nature of MCHM and how the polyQ tracts of Med15 as part 
of the fuzzy domain that? interact to form protein folding aggregations. Proteins with intrinsically disordered domains like polyQ tracts can shift into LLPS in the presence of a hydrotrope with a change in solubility and protein complex conformation. Therefore, the fuzzy domains of Med15 and the expansion of polyQ tracts were consequently responsible for the phenotypic diversity seen in growth assays.

While assessing the yeast cells' sensitivity towards MCHM, what I found interesting was how the presence of the Myc tag affected how cells respond in stressful conditions. The phenotypic differences between the two Med15 alleles were obvious in MCHM when

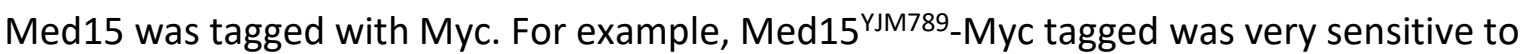
MCHM with almost no growth observed, while untagged Med15 $5^{\mathrm{YJM} 789}$ was not sensitive and, in fact, had similar growth to Med15 ${ }^{\mathrm{s} 288 \mathrm{c}}$. Further investigation into the effects of the Cterminal Myc tag showed that these different growth phenotypes were not just observed when cells were exposed to MCHM but also when cells were exposed to other chemical stressors. There are times where the Myc tag flipped the sensitivity of the allele or exaggerated the differences. Myc is a polypeptide protein tag that shares sequence similarity with the DNA binding domain of Pho4 (Fisher et al., 1991). Pho4, a basic helixloop-helix transcription factor required for phosphate metabolism, physically interacts with Snf1 (Graumann et al., 2004). Because Snf1 interacts with the Mediator complex (Uthe et al., 2017), it is possible that the Myc tag is a target of phosphorylation by Snf1, which in turn impacts how Med15 interacts with stress-induced transcription factors. Growth assays had shown that in the snf1 knockout, the changes observed when polyQ tracts were swapped were only obvious when Med15 was Myc tagged, which further supports the idea that Snf1 phosphorylates Myc in vitro. 
Reg1 is a known negative regulator of Snf1, and deleting it over-activates Snf1 (Tu and Carlson, 1995). The loss of Reg1 improved cell growth in the presence of MCHM compared to snf1 and med15 mutants. In most cases, both Med15 and Snf1 as stress response regulators have proven to be important for a cell's survival and evolution. An overactive Snf1 in reg1 mutant cells allows for enhancing the stress response pathway, ensuring that the cells are still alive and growing. Multiple isoforms of Med15-Myc tagged protein were detected when the pattern of Med15 bands in snf1 and reg1 mutants was measured using western blot. The levels of Med15 ${ }^{\mathrm{YJM} 789}$ decrease slightly compared to Med15 ${ }^{\mathrm{S} 288 \mathrm{c}}$ in the snf1 mutant, similar to the wildtype Med15. However, in the reg1 mutant, the levels of Med15 YJM789 increased, but the band was noticeably shifted upwards. Although Med15 ${ }^{\mathrm{YJM} 789}(142 \mathrm{kDa})$ is larger than Med15 ${ }^{\mathrm{S288c}}(140 \mathrm{kDa})$, it appears that Med15 ${ }^{\text {YJM789 }}$ ran much faster than Med15 $5288 \mathrm{c}$ in electrophoresis, possibly due to post-translational modifications.

There were no particular patterns observed between the two genetically diverse Med15 alleles when cells were subjected to various chemical stressors, whereby one allele dominated the quantitative growth assay with its resistivity. Both alleles had the equal capacity to overcome these stressors, which supports our hypothesis. For example,

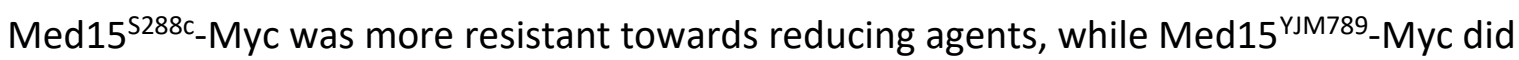
much better in calcofluor white.

With the knowledge that we have regarding the genetic variations of the two Med15 alleles and their varying ability to deal with stressful conditions, we wanted to continue exploring 
Med15's interactions and other pathways involved. In Chapter 4, we discovered that the use of myc antibody beads for further analysis lacked binding capacity resulting in poor protein detection in western blots and silver stained gels. Since we've also learned that the Cterminal Myc tag affects Med15 through phosphorylations by Snf1, we proposed using TurbolD, a proximity labeling technique recently developed in yeast. A shorter labeling time with a more robust binding capacity through streptavidin beads may allow us to identify Med15 associating proteins with fewer contaminants and improved precision. Med15 and the entire Mediator complex are heavily phosphorylated during non-stress conditions to prevent stress response transcription (Miller et al., 2012). Future research into posttranslational modifications of Med15 using TurbolD will expand our knowledge on how post-translational modifications help regulate Med15's interactions. Were the differences observed in Chapter 3 between the two varying Med15 alleles (YJM789 and S288c) solely due to the genetically diverse polyQ tracts, or do post-translational modifications play a role in it as well?

In summary, this thesis work has contributed to the understanding of MCHM as a novel hydrotropic stressor that induces LLPS to affect the yeast stress response. The genetic variation between two Med15 alleles had an effect on how yeast cells respond to a hydrotropic stressor like MCHM. Stress response regulators, Snf1 and Reg1 is found to not only affect MCHM sensitivity but also affects how cells deal with other types of drugs. The studies that we've conducted add knowledge to the field of systems biology and genetics by elucidating the dependency of stress response regulators on genetic variations and their interactions with other proteins. 


\section{REFERENCES}

Benson, S.M., Ruestow, P., Keeton, K.A., Novick, R.M., Marsh, G.M., and Paustenbach, D.J. (2018). The 2014 crude 4-methylcyclohexanemethanol chemical release and birth outcomes in West Virginia. Archives of Environmental \& Occupational Health 73, 292-301.

Fisher, F., Jayaraman, P.S., and Goding, C.R. (1991). C-myc and the yeast transcription factor PHO4 share a common CACGTG-binding motif. Oncogene 6, 1099-1104.

Foreman, W.T., Rose, D.L., Chambers, D.B., Crain, A.S., Murtagh, L.K., Thakellapalli, H., and Wang, K.K. (2015). Determination of (4-methylcyclohexyl)methanol isomers by heated purge-and-trap GC/MS in water samples from the 2014 Elk River, West Virginia, chemical spill. Chemosphere 131, 217-224.

Graumann, J., Dunipace, L.A., Seol, J.H., McDonald, W.H., Yates, J.R., Wold, B.J., and Deshaies, R.J. (2004). Applicability of tandem affinity purification MudPIT to pathway proteomics in yeast. Mol Cell Proteomics 3, 226-237.

Miller, C., Matic, I., Maier, K.C., Schwalb, B., Roether, S., Strässer, K., Tresch, A., Mann, M., and Cramer, P. (2012). Mediator Phosphorylation Prevents Stress Response Transcription During Non-stress Conditions. Journal of Biological Chemistry 287, 44017-44026.

Perfetto, M., Kirkham, S.G., Ayers, M.C., Wei, S., and Gallagher, J.E.G. (2020). 4Methylcyclohexane methanol (MCHM) affects viability, development, and movement of Xenopus embryos. Toxicol Rep 8, 38-43. 
Pupo, A., Ayers, M.C., Sherman, Z.N., Vance, R.J., Cumming, J.R., and Gallagher, J.E.G. (2020). MCHM Acts as a Hydrotrope, Altering the Balance of Metals in Yeast. Biol Trace Elem Res 195, 260-271.

Tu, J., and Carlson, M. (1995). REG1 binds to protein phosphatase type 1 and regulates glucose repression in Saccharomyces cerevisiae. EMBO J 14, 5939-5946.

Uthe, H., Vanselow, J.T., and Schlosser, A. (2017). Proteomic Analysis of the Mediator Complex Interactome in Saccharomyces cerevisiae. Scientific Reports 7. 